\title{
Anabases
}

ANABASES Traditions et réceptions de l'Antiquité

$22 \mid 2015$

Varia

\section{Relire le Satyricon. Pline le Jeune et les chrétiens, cibles du roman secret d'un affranchi cultivé}

\section{Stéphane Ratti}

\section{(2) OpenEdition}

1 Journals

Édition électronique

URL : http://journals.openedition.org/anabases/5463

DOI : 10.4000/anabases.5463

ISSN : 2256-9421

Éditeur

E.R.A.S.M.E.

\section{Édition imprimée}

Date de publication : 20 octobre 2015

Pagination : 99-145

ISSN : 1774-4296

\section{Référence électronique}

Stéphane Ratti, «Relire le Satyricon. Pline le Jeune et les chrétiens, cibles du roman secret d'un affranchi cultivé », Anabases [En ligne], 22 | 2015, mis en ligne le 20 octobre 2017, consulté le 20 octobre 2019. URL : http://journals.openedition.org/anabases/5463 ; DOI : 10.4000/anabases.5463

(c) Anabases 


\section{Relire le Satyricon. Pline le Jeune et les chrétiens, cibles du roman secret d'un affranchi cultivé}

Stéphane RatTi

\section{Première partie L'auteur du Satyricon, un familier de Pline le Jeune}

- auteur du Satyricon connaissait bien la correspondance de Pline le Jeune. Il y a puisé un certain nombre de thèmes ou de situations caractéristiques de la vie intellectuelle du début du $\mathrm{II}^{\mathrm{e}}$ siècle ainsi que de la condition des affranchis. Ces parallèles fournissent un argument sûr pour refuser l'identification de l'auteur du Satyricon avec le consulaire Petronius mentionné par Tacite. Ils établissent que le roman a été écrit après l'année Io7 et peut-être après III, très probablement au début du II $^{\mathrm{e}}$ siècle. Ils confirment enfin de manière éclatante la thèse qui voit en Encolpius, l'affranchi de Pline le Jeune, l'auteur du Satyricon.

Cette nouvelle datation du roman, éloigné désormais de toute espèce de relation avec les temps néroniens, ouvre la voie, dans la continuité d'une contextualisation refondée, à de nouvelles pistes de lecture. Non seulement Trimalchion n'est pas dans le Satyricon l'arriviste obtus que l'on dépeint ordinairement, mais encore l'auteur du roman éprouve pour lui une forme de solidarité qu'expliquent leurs origines sociales communes. La vraie cible de l'œuvre n'est pas l'hôte du fameux festin, mais l'homme, Pline le Jeune, dont la vie et la condition mais aussi la riche activité littéraire inspirent un romancier qui était aussi son conseiller culturel. 


\section{La décadence de l'école: un motif dans l'actualité du II siècle}

Le Satyricon s'ouvre pour nous sur une violente et fort savoureuse dénonciation de la baisse générale du niveau des élèves que le système éducatif du temps - à vrai dire les écoles de rhétorique, mais c'est à l'époque la même chose -, et leurs maîtres demi-savants, les umbratici doctores (2, 4), ont profondément décervelés: adulescentulos existimo in scholis stultissimos fieri se lamente Encolpe; “je crains que les jeunes à l'école ne deviennent parfaitement idiots » (sat. I, 3). Le motif est de tous les temps et de tous les lieux et n'a pas même paru incongru à un Victor Hugo dénonçant, dans Les Misérables, l'abrutissement scolaire par la bouche du fort sympathique "philosophe» membre du cercle des “Amis de l'Arc», le dénommé Combeferre:

“Il déclarait que l'avenir est dans la main du maître d'école, et se préoccupait des questions d'éducation. Il voulait que la société travaillât sans relâche à l'élévation du niveau intellectuel et moral, au monnayage de la science, à la mise en circulation des idées, à la croissance de l'esprit dans la jeunesse, et il craignait que la pauvreté actuelle des méthodes, la misère du point de vue littéraire borné à deux ou trois siècles classiques, le dogmatisme tyrannique des pédants officiels, les préjugés scolastiques et les routines ne finissent par faire de nos collèges des huîtrières artificielles ${ }^{1}$. »

Le lecteur du Satyricon dans la “Collection des Universités de France» ne se voit pas sans surprise renvoyé par les premières notes de l'éditeur censées éclairer la diatribe d'Encolpe à des auteurs tous postérieurs à l'époque néronienne². A. Ernout, était, on le sait, un partisan de la thèse traditionnelle qui voit en l'auteur du Satyricon le Pétrone mentionné par Tacite (ann. I6, I7-I9), soit le «personnage consulaire, contemporain et familier de Néron que la jalousie de Tigellin fit mettre à mort ${ }^{3}$ » en l'an 65 de notre ère. On ne peut qu'être frappé par l'aveugle clairvoyance du célèbre latiniste. Je m'explique: il faut en effet rendre tout d'abord hommage à sa sagacité car tous les rapprochements qu'il propose entre sat. I-4 et Quintilien (inst. I2, I0, I6 sqq. $)^{4}$ ou Tacite (dial. $\left.28-29\right)^{5}$ sont parfaitement probants, sans parler

1 V. Hugo, Les Misérables, éd. Hetzel-Quantin, Paris, s. d. (I88I), vol. 3, p. I4r. L'éditeur de Victor Hugo, J.Hetzel, ajoute ailleurs, dans sa Préface aux Châtiments que ses poèmes “comme les Annales de Tacite, comme les Satires de Juvénal, sont un livre d'éducation pour les peuples, - ces enfants qui ont tant de peine à mûrir », Les Châtiments, seule édition complète, Hetzel, Paris, s. d. (I869), p. III. - Sauf mention contraire, je suis responsable de toutes les traductions dans cette étude.

2 A. Ernout, Le Satiricon, Paris, cuf, I923.

3 A. Ernout, p. VII.

4 A. Ernout, note I, p. 2.

5 A. Ernout, note 2, p.3. 
de l'évocation fugace des noms de Martial et de Pline le Jeune ${ }^{6}$, intuition exprimée au passage, fondamentalement juste mais inexplicablement inaboutie puisqu'elle ne débouche sur aucune conclusion. Il faut surtout s'étonner de son aveuglement: comment persister dans une datation néronienne du roman alors que la très riche intertextualité du débat sur la décadence de l'enseignement conduit de manière irréfutable au début du II $^{\mathrm{e}}$ siècle? Faut-il penser que le poids de la tradition, l'opinio communis et l'autorité académique de quelques maîtres, ont fermé les yeux non au philologue, qui avait vu juste, mais à l'universitaire qui n'avait su tirer toutes les conséquences de ses observations? La leçon, du point de vue épistémologique, me paraît d'une grande force. Mais Pascal, dans les Pensées, l'a dit mieux que je ne saurais le faire: “Ceux qui sont accoutumés à juger par le sentiment ne comprennent rien aux choses du raisonnement, car ils veulent d'abord pénétrer d'une vue et ne sont point accoutumés à chercher les principes ${ }^{7}$.»

\section{L'auteur du Satyricon a lu Martial et Tacite}

Les recherches menées depuis maintenant plusieurs années par René Martin sur la datation du Satyricon ont bouleversé les données traditionnelles du problème et permis des avancées considérables ${ }^{8}$. Il me paraît notamment - je les ai moimême patiemment vérifiées point par point - que les observations qu'il propose, à la suite de quelques autres, sur les loci similes rencontrés dans le Satyricon d'une part, Silius Italicus, Martial, Tacite (Dialogue des orateurs) et Pline le Jeune d'autre part sont irréfutables ${ }^{9}$. Je ne peux ici les citer tous et je me contenterai de rappeler que le nom même de Trimalchion a été inspiré à l'auteur du Satyricon par la satire 3, 82 de Martial où apparaît un débauché du nom de Malchio ${ }^{10}$, mais sans doute trois fois moins dépravé que l'amphitryon de la cena, le nom de ce dernier ayant été fabriqué sur le modèle du Trinummus plautinien, le procédé même qui servira encore à Molière pour baptiser son Trissotin. Tout aussi significatif est le fait que le parfumeur Cosmus cité par Martial dans cette même pièce (vers 26-28: “Parfumé des essences que renferment les bocaux de Cosmus, il ne répugne pas à nous distribuer, dans un murex doré, la pommade qui sert aux cheveux d'une

6 A. Ernout, note I, p.4.

7 Pensées 23, p. Iog4 Chevalier (Pensées 3 Brunschvic), Paris, I954 (Bibliothèque de la Pléiade).

8 Cf. notamment “Qui a (peut-être) écrit le Satyricon? ”, Revue des Études Latines 78, 200o, p. 139-ı63; et id., Le Satyricon. Pétrone, Paris, I999.

9 Pour Martial, cf. déjà A. Colligon, Étude sur Pétrone. La critique littéraire, l'imitation et la parodie dans le Satiricon, Paris, 1892, p. 39I-395.

10 Martial 3, 82, 32: Hoc Malchionis patimur inprobifastus; « nous subissons la morgue de ce débauché de Malchion ». 
infâme courtisane ${ }^{11}$ ) ) ait sans aucun doute possible inspiré un passage perdu du Satyricon dont Niccolo Perotti, au $\mathrm{xv}^{\mathrm{e}}$ siècle, nous a sauvegardé les débris: “Cosmus était un grand parfumeur qui a donné son nom aux parfums Cosmaniens [...]. Pétrone dit: "Apporte nous une fiole de Cosmanien 12". „ Or Cosmus est parfaitement inconnu avant Martial ${ }^{13}$ et la référence pétronienne au satiriste fournit assurément désormais un point fixe pour la datation du roman après Io2, date de la mort du poète ${ }^{14}$.

Je me permettrai d'ajouter à la déjà longue liste des rapprochements incontestables entre Martial et Pétrone établie par René Martin deux points supplémentaires. Le fragment 8 de Pétrone, transmis par Fulgence ${ }^{15}$, nous apprend qu'Ascylte et Encolpe se font servir à boire par Quartilla, au cours de l'épisode licencieux bien connu ${ }^{16}$, dans des vases myrrhins, cette vaisselle précieuse élaborée dans une matière mal connue, ou bien une porcelaine d'origine orientale ou bien encore une variété d'agate: Petronius Arbiter ad libidinis concitamentum myrrhinum se poculum bibisse refert; “Pétrone Arbiter rapporte qu'il but dans une coupe myrrhine afin d'éveiller son désir ». Or le débauché Malchion qui est la cible de la satire 82 de Martial fait exactement de même et sert son vin vieux dans des coupes myrrhines: “Il verse à ses bouffons le nectar d'Opimius dans des vases de cristal et de myrrhe ${ }^{17}$.»

Ce vin « opimien » est daté par le consulat d’Opimius en I2I avant J.-C., une année proverbialement exceptionnelle, mais évidemment bien trop lointaine pour avoir été réellement bue encore à l'époque de Martial, ainsi que le confirme Velleius Paterculus qui, sous Tibère, faisait déjà la même constatation ${ }^{18}$.

11 Martial 3, 82, 26-28: et Cosmianis ipse fusus ampullis / non erubescit murice aureo nobis / diuidere moechae pauperis capillare.

12 Frg. I8, p.I85-186 Ernout: Cosmus etiam excellens unguentarius fuit, a quo unguenta dicta sunt Cosmiana [...]. Petronius: "Affer nobis, inquit, alabastrum Cosmiani».

13 Cf. aussi Juvénal 8, 85-86: Dignus morte perit, cenet licet ostrea centum / Gaurana et Cosmi toto mergatur aeno; “Celui qui mérite de mourir, c'est comme s’il était déjà mort, même s'il dîne d'une centaine d'huîtres du Gaurus et qu'il se plonge dans tous les parfums de Cosmus».

14 R. Martin, “Qui a (peut-être) écrit le Satyricon? » (cité note 8), p. I48.

15 P. I83 Ernout.

16 Sat. I6-ı8. C'est une glose qui figure dans le mss Parisinus 7975 qui donne une double précision précieuse : les vases myrrhins sont fournis par Quartilla et cet épisode prenait place au livre i4 du roman: cf. apparat critique du frg. 8, p. I83 Ernout.

17 Martial 3, 82, 24-25: Opimianum morionibus nectar / Crystallinisque murrinisque propinat.

18 Velleius Paterculus 2, 7, 5-6: Hic est Opimius, a quo consule celeberrimum Opimiani uini nomen; quod iam nullum esse spatio annorum colligi potest, cum ab eo sint ad te, 
Ce que l'on ne dit pas, à ma connaissance, c'est que c'est précisément le même vin que se fait servir Trimalchion au cours de la cena:

Statim allatae sunt amphorae uitreae diligenter gypsatae, quarum in ceruicibus pittacia erant affixa cum hoc titulo: Falernum Opimianum annorum centum (sat. 34, 6);

“Sur le champ on apporta des amphores en verre bouchées avec soin aux cols desquels avaient été accrochées des étiquettes avec cette inscription: "Falerne Opimien - Cent ans d'âge". »

Il me paraît donc certain qu'il faut abandonner l'identification du Petronius Arbiter donné comme auteur du Satyricon par les manuscrits avec le Petronius tacitéen des chapitres I7-I9 du livre i6 des Annales. Jamais en effet Tacite ne présente ce haut personnage comme un homme de lettres et il n'aurait assurément pas manqué de le faire si la chose avait eu quelque réalité. La formule si commentée de ann. I6, I8, elegantiae arbiter, ne prouve rien.

Ou plutôt si: elle explique tout.

Le passage de Tacite en question a très probablement inspiré l'auteur du Satyricon qui a écrit son roman sous un pseudonyme. On sait combien la tradition littéraire occidentale est riche de pseudonymes cryptés, ironiques ou humoristiques, et je citerai, pour me cantonner à la période contemporaine, simplement les noms d'Émile Ajar ou celui d'Edgar Faure: le premier, connu aussi sous le nom de Romain Gary, non seulement remporta deux prix Goncourt sous ses deux hypostases pour Les Racines du ciel en I956 et pour La Vie devant soi en I975, mais encore choisit deux noms qui ont en commun leur étymologie russe et leur signification associée au feu pour le premier, à la braise pour le second. On sait en revanche peu que l'ancien ministre de la Quatrième et de la Cinquième République Edgar Faure fut un excellent auteur de romans policiers: Pour rencontrer M. Marsches et L'installation du président Fritz-Mole. Le plus connu reste M.Langlois n'est pas toujours égal à lui-même qu'il publie sous le pseudonyme d'Edgar Sanday (Sandé) parce que son prénom s'écrivait sans la lettre D.

Or les Romains de l'époque impériale pratiquaient l'art du pseudonyme comme le prouve ce recueil de biographies impériales de la fin du $\mathrm{Iv}^{\mathrm{e}}$ siècle et que l'on nomme (faute de nom d'auteur) l'Histoire Auguste. Ce sont même six noms d'emprunt (Julius Capitolinus ou Flavius Vopiscus par exemple) que le faussaire a inventé pour la circonstance, non sans jeu de mot subtil dans le choix de ses faux

M. Vinici, consulem anni CLI; “C'est ce même Opimius dont le consulat a donné son nom au célèbre vin opimien. Mais il n'en reste plus, comme on peut le penser en calculant les années depuis cette époque et ton consulat, soit cent cinquante et un ans ». 
patronymes ${ }^{19}$. L'auteur du Satyricon est donc loin d'être un cas isolé dans la tradition des imposteurs férus de littérature.

\section{L’auteur du Satyricon connaissait la correspondance de Pline le Jeune}

La chronologie et l'histoire de la réception des lettres de Pline le Jeune dans l'Antiquité doivent probablement être revues. On estime en effet généralement que le Panégyrique de Trajan, par son éclat, a éclipsé la correspondance. Personne n'aurait ainsi lu les lettres de Pline entre les $\mathrm{II}^{\mathrm{e}}$ et $\mathrm{IV}^{\mathrm{e}}$ siècle $^{20}$, soit avant Symmaque à la fin du $\mathrm{rv}^{\mathrm{e}}$ siècle et la connaissance par l'orateur païen du corpus plinien paraît assurée ${ }^{21}$. Comme l'écrit Philippe Bruggisser, «Symmaque aurait été sensible à l'analogie entre les souffrances que les sénateurs ont endurées sous le joug de Domitien et sous celui de Valentinien I ${ }^{\mathrm{er}}$ et les espoirs qu'ont fait naître le règne de Nerva et celui de Gratien ${ }^{22}$ ». Il est vrai que Pline le Jeune lui-même, s'il raconte les succès des lectures qu'il donnait de ses discours (epist. 3, I8; 4, 5) ou de ses poèmes (epist. 8, 2I) n'évoque jamais la moindre recitatio de ses lettres. L'histoire de la publication des Lettres ne peut être faite, même s'il est hautement vraisemblable que Pline y a pourvu lui-même, sans doute à une date tardive.

Ce que je voudrais à présent avancer, c'est que les lettres de Pline eurent très tôt un lecteur attentif, son contemporain, l'auteur du Satyricon.

Le premier Luigi Pepe avait, en I958, suggéré avec force que l'auteur du Satyricon avait lu la correspondance de Pline et il appuyait son hypothèse sur la ressemblance entre sat. II5, 6 et la lettre de Pline à Tacite décrivant l'éruption du Vésuve (epist. 6, 20, I9) ${ }^{23}$. Mais son article ne semble pas avoir eu grand retentissement. René Martin à son tour relève certains liens thématiques qui existent entre l'œuvre de Pline le Jeune et le Satyricon: le motif par exemple de la captatio des héritages (epist. 8, I8) ou encore celui des loups-garous ou autres striges et fantômes (epist. 7 , 27) ${ }^{\mathbf{2 4}}$. Il faut les enregistrer avec attention.

19 Cf. St. Ratti, Écrire l'Histoire à Rome, Paris, 2009, p. 285-29ı. - Pour les pseudonymes voir encore, infra, les deux chapitres conclusifs.

20 Panorama complet de “La postérité des Lettres de Pline le Jeune par É. Wolff, Pline le Jeune ou le refus du pessimisme, Rennes, 2003, p. 95-98.

21 Cf. Ph. Bruggisser, Symmaque ou le rituel épistolaire de l'amitié littéraire. Recherches sur le premier livre de la correspondance, Fribourg, I993, p. IIo-III (idéal de la simplicitas) et p.224-225.

22 Symmaque (cité note 2I), p.225.

23 L. Pepe, “Petronio conosce l'epistolario di Plinio », Giornale Italiano di Filologia II, I958, p. $289-294$.

24 R. Martin, “Qui a (peut-être) écrit le Satyricon? » (cité note 8), p. I5o. 
Mais surtout l'identification par René Martin de l'auteur du Satyricon en la personne d'un affranchi de Pline le Jeune, un intellectuel érudit du nom d'Encolpius, me paraît lumineuse dans son évidence et absolument probante ${ }^{25}$. J'ajoute à présent, dans les pages qui suivent, quelques nouveaux arguments en faveur de cette thèse.

Cet homme, Encolpius, membre de la familia de Pline au sens premier du mot latin, faisait aussi partie de ses «familiers» au sens courant du terme en français moderne: il comptait au nombre des intimes de son maître. On voit ce dernier se promener dans ses propriétés entouré des membres de sa familia, parmi lesquels de vrais érudits: “Il m’arrive de flâner avec mes gens et parmi eux des intellectuels $^{26}$. » Les fonctions de lector exercées par Encolpius (epist. 8, I, 2) doivent être comprises dans la plus grande extension possible du terme. On lisait en effet dans la société de ce temps à haute voix ${ }^{27}$. Titinius Capito, le contemporain et correspondant de Pline, lisait lui-même ses ouvrages ${ }^{28}$. Mais Pline pour sa part lisait mal, ne savait pas prononcer les vers, et on lui en faisait le reproche: «Apporte une solution à mes doutes ; j'entends dire que je suis mauvais lecteur, que je lis mal notamment les vers ${ }^{29}$. . Aussi faisait-il appel à l'un de ses affranchis, peut-être Encolpius, pour faire connaître ses propres vers à ses amis : «Je songe par conséquent pour une lecture que je compte faire à des amis proches à tester mon affranchi. Ce que j’ai choisi lui est aussi familier et il le lira, je le sais, non pas parfaitement mais mieux que moi ${ }^{30}$. „ Encolpius faisait en outre à son maître les lectures qui agrémentaient les divers moments de ses journées et il s'agit cette fois des ouvrages d'autrui: cenanti mihi, si cum uxore uel paucis, liber legitur ${ }^{31}$. Les auteurs lus par Encolpius doivent être ceux que mentionne Pline dans ses lettres et l'on retrouve

25 R. Martin, “Qui a (peut-être) écrit le Satyricon? „ (cité note 8), p. I56-ı59; cf. Pline, epist. 8, I, I-3. Afin d'éviter toute ambiguïté je nomme, dans la suite de cette étude, “Encolpius » l'auteur du Satyricon et «Encolpe» le personnage du roman.

Epist. 9, 36, 4: mox cum meis ambulo, quorum in numero sunt eruditi.

27 Epist. 8, I3, I (à Genialis) : probo quod libellos meos cum patre legisti; “ J'approuve que tu aies procédé à la lecture de mes livres devant mon père».

28 Epist. 8, 12, I: recitaturus est Titinius Capito quem audire nescio magis debeam an cupiam; “C'est Titinius Capito qui procédera à la lecture. L'écouter est pour moi un devoir ou un souhait, je ne sais ».

29 Epist. 9, 34, I: explica aestum meum; audio me male legere, dumtaxat uersus.

30 Epist. 9, 34, I: cogito ergo recitaturus familiaribus amicis experiri libertum meum. Hoc quoque familiare quod elegi non bene, sed me melius, scio, lecturum.

31 Epist. 9, 36, 4. 
ainsi l'explication des parallèles enregistrés entre le Satyricon et Quintilien, Martial ou Silius Italicus ${ }^{32}$.

\section{Comment Pétrone a choisi son nom de plume}

Cet homme - ou ses pareils s'ils étaient plusieurs - était ainsi placé par ses fonctions au cœur de l'activité intellectuelle de Pline et savait tout non seulement des productions de son maître, qu'elles soient en cours de gestation ou achevées, mais encore de l'actualité littéraire par le biais des lettres reçues par Pline ou des ouvrages qu'on adressait en hommage à l'une des personnalité les plus en vues de son temps ${ }^{33}$. On connaît cette anecdote piquante rapportée par Pline et qui prouve que Tacite et lui-même passaient pour les deux plus grands écrivains de leur temps ${ }^{34}$. Comment Encolpius aurait-il pu ignorer dans ces conditions la proximité de Pline avec Tacite? Il avait transcrit, lu, corrigé peut-être les onze lettres de Pline à Tacite ${ }^{35}$ et il avait lu les pages des Annales envoyées par Tacite à son ami comme il était informé de la parution des Histoires (epist. 9, 27, I) ${ }^{36}$. Cela ne fait aucun doute: c'est là qu'il a trouvé l'idée d'un Arbiter Petronius, fabriqué par jeu littéraire en associant Petronius et elegantiae arbiter (ann. I6, I8).

L'auteur du Satyricon a choisi son nom de “plume p par référence à un passage bien caractérisé de l'ouvrage historique du plus grand historien vivant de son temps: Tacite. Comme Trimalchion qui affirme dans son épitaphe funéraire n'avoir jamais entendu la leçon d'aucun philosophe ${ }^{37}$, Petronius, chez Tacite, meurt «sans vouloir écouter ni réflexions sur l'immortalité de l'âme ni propos de philosophes ${ }^{38}$ » mais plutôt des “poésies légères et des vers gais ${ }^{39}$ ». Loin de prouver que Petronius est l'auteur du Satyricon, je considère plutôt que ces propos ont

32 Quintillien est cité par Pline dans epist. 2, I4, 9; Martial dans epist. 3, 2I ; Silius Italicus dans epist. 3,7 .

33 Ouvrage envoyé à Pline, cf. par exemple epist. 9, I, 2; 9, 22, I-2 ; 9, 28, 3 ; 9, 3I ; composition envoyée par Pline, cf. par exemple epist. 9, 4, I; 9, I8, 2; 9, 20, I; 9, 25. Sur les insertions des compositions de Pline dans les ouvrages de ses amis et inversement, cf. par exemple epist. 9, II, I. - Sur Pline écrivain on pourra consulter le très suggestif ouvrage d'É. Wolff, Pline le Jeune (cité note i7), p. 83-98.

34 Epist. 9, 23, I-3: Tacite a raconté à Pline, qui, fort flatté, le rapporte à son tour, qu'un chevalier assis à ses côtés aux jeux du cirque l'a confondu avec Pline. Epist. I, 6; I, 20; 4, I3; 6, 9; 6, I6; 6, 20; 7, 20; 7, 33; 8, 7; 9, I0; 9, I4.

36 Il est tout à fait possible que les fonctions de lector ne soient pas très éloignées des charges d'un notarius ou d'un scribe: cf. epist. 9, 36; 9, 40.

37 Sat. 7I, I2: nec umquam philosophum audiuit; “jamais il n'a écouté de philosophe».

38 Ann. 16, I9, 2: audiebatque referentes nihil de immortalitate animae et sapientium placitis. Ann. 16, I9, 2 : sed leuia carmina et faciles uersus. 
plu par leur étrangeté et leur ton inhabituel à l'amateur de plaisanteries qui y a trouvé le prétexte du pseudonyme adopté pour signer son roman.

Peut-être peut-on avancer une ultime explication: le consulaire Petronius fut, aux dires de Tacite gouverneur de la province de... Bithynie ${ }^{40}$, la région même à la tête de laquelle Pline le Jeune a été nommé par Trajan en 111! Formons une hypothèse: Encolpius, l'affranchi de Pline, libéré de la présence de son patron qui, absent pendant deux ou trois ans, décède en Bithynie en II3 ou Iı4, a relâché sa surveillance sur sa domus, a bien pu mettre à profit cette demi-liberté, loin de la censura tutélaire du maître, pour composer le Satyricon qu'il faudrait dès lors placer après III. Dans ce cas de figure Pline n'aurait jamais rien su de l'existence d'un roman bien trop scandaleux pour avoir été présenté à son approbation.

\section{L'auteur du Satyricon est un affranchi et non un aristocrate}

L'auteur du Satyricon est donc un affranchi et non un aristocrate. Ainsi s'effondrent définitivement toutes les hypothèses de lecture fondées sur la prétendue supériorité de caste de l'auteur et son mépris pour le monde vulgaire, grossier et inculte des liberti dont Trimalchion serait l'emblème majeur et à peine caricaturé. Il convient désormais de conserver toujours à l'esprit qu'Encolpius (auteur du Satyricon) appartient au monde même de Trimalchion, ce monde avide de reconnaissance sociale et d'affirmation de soi par l'argent si bien décrit par Paul Veyne $^{41}$. Ainsi s'explique qu'Encolpe (personnage du Satyricon) n'accepte pas que les critiques de ses deux compères Ascylte et Giton à l'encontre de Trimalchion aillent trop loin dans la cruauté: il juge leurs quolibets déplacés (sat.57, I intemperantis licentiae) et indécents (58, I: indecenter) et les rappelle à l'ordre au nom d'une solidarité de classe qui ne dit pas son nom.

C'est dans la correspondance de Pline que l'on trouve le meilleur témoignage pour tenter de comprendre ce qu'un intellectuel devait ressentir à subir la morgue d'un aristocrate qui faisait perpétuellement peser sur lui le joug de la dépendance financière. Il ne s'agit de rien d'autre que de cette lettre appelée parfois à tort “Éloge de Martial» dans laquelle Pline se pose en défenseur des Lettres et des Arts. On annonce à Pline le décès de l'épigrammatiste. L'épistolier se livre alors à un éloge bref qui le conduit très vite à l'objectif réel et unique de la lettre: rappeler les vers dans lesquels Martial a fait l'éloge de son talent littéraire, raison pour laquelle cette epistula 2I du livre 3 devrait en réalité s'appeler «Éloge de Pline par Martial » et non “Éloge de Martial par Pline»! Ces dix vers, en outre, Pline les cite complaisamment in extenso (epist. 3, 2I, 4), ce qui se comprend bien puisque

\footnotetext{
40 Ann. 16, I9, 2: proconsul tamen Bithyniae.

41 “Vie de Trimalcion », La société romaine, Paris, I99I, p. I3-87.
} 
Martial ne fait pas moins que de comparer, pour leur qualité, les discours de Pline à ceux du grand Cicéron ${ }^{42}$. Mais ce n'est pas tout: Pline rappelle encore au passage qu'il a aidé financièrement Martial au moment du départ du poète pour sa patrie: prosecutus eram uiatico secedentem; “je lui avais fait un don, au moment de son départ, pour son voyage » et qu'il s'est ainsi conformé à la vieille et noble tradition du mécénat des patroni en faveur de leurs clients. Et puis in cauda uenenum: la lettre s'achève en effet par une pique à la fois brillante et méprisante. Après avoir fait mine de croire l'espace d'un instant que les œuvres de Martial passeraient à la postérité, Pline dénonce férocement les illusions du poète:

- At non erunt aeterna quae scripsit? Non erunt fortasse, ille tamen scripsit tamquam essent futura;

- «Mais, diras-tu, ses œuvres ne seront pas éternelles? Sans doute que non, mais lui, il les a écrites dans l'idée qu'elles le seraient!»

Pour nous l'ironie de Pline fait le charme de ses lettres, comme elle le fait de la Correspondance de Madame de Sévigné lorsque la malignité s'empare d'elle, ce qui arrivait quelquefois, ou de certaines lettres de Gide à Claudel, qu'il détestait. Mais que devait penser d'une telle attitude notre Encolpius qui ne pouvait sans doute s'interdire de rapprocher de son propre cas le mépris exprimé par Pline envers un eruditus de seconde classe? À l'appui de l'identification d'Encolpius avec l'auteur du Satyricon, citons ce passage en vers du début du roman dans lequel le vieux professeur d'Encolpe fait une analyse de la décadence de l'enseignement pleine de bon sens et donne à l'apprenti écrivain de sages conseils, parmi lesquels celui-ci:

Nec curet alto regiam trucem uultu

cliensue cenas inpotentium captet,

nec perditis addictus obruat uino

mentis calorem; neue plausor in scenam

sedeat redemptus histrioniae addictus ${ }^{\mathbf{4}}$.

“Qu'il ne se préoccupe pas des demeures hautaines où l'on porte le menton haut; qu'il n’aille point en client fréquenter les festins de tyrans ni se livrer aux débauchés et perdre sous l'effet de la boisson la force de son esprit; qu'il n'aille pas, payé pour cela, faire la claque et applaudir assis devant la scène la comédie que l'on donne.»

Je crois que ces vers, sincères de la part non seulement d'Agamemnon mais aussi d'Encolpius, expriment le grand désenchantement voire l'amertume d'un

42 Epist. 3, 2I, 4: Hoc quod saecula posterique possint / Arpinis quoque comparare chartis; “Les siècles à venir et la postérité pourront bien les égaler aux écrits de l'Arpinate».

43 Sat. 5, 4-8. 
intellectuel contraint par sa situation sociale et ses origines serviles de continuer à servir après son affranchissement même. Que dénoncent ces vers? La situation même d'Encolpius, l'auteur du Satyricon. Il n'est question ici ni de théâtre véritable ni d'histrion au sens propre. La scène évoquée est celle du monde de Pline et l'histrion est le maître auquel son lector est condamné jour après jour à servir flagorneries et autres petitesses. Il ne saurait y avoir d'intellectuel que libre et la métaphore du vin des festins - la vie dans l'entourage de Pline n'avait rien d'une bacchanale - n'est qu'un travestissement. L'essentiel est dit: un écrivain, un homme de lettres, un intellectuel ne saurait vendre l'indépendance de son génie (mentis calor) à aucun prix. Agamemnon dénonce la prostitution littéraire du temps et Encolpius la sienne propre. On comprend mieux désormais pourquoi il le fait sous un pseudonyme!

Je crois profondément que l'ambiguïté sociale du statut d'affranchi qui est celui de son auteur explique un grand nombre des aspects jugés jusqu'ici peu compréhensibles du Satyricon. La situation sociale et la position intellectuelle d'Encolpius, à la fois proche de Pline et l'admirant, fasciné en tout cas par ce que représente le personnage dans le monde littéraire du temps, mais essentiellement méprisé de lui, le sachant parfaitement, en souffrant sans doute, cette ambiguïté de classe donc qui est à la source des sentiments tiraillés du lector pour son patron expliquent l'ambiguïté consubstantielle du Satyricon et son ironie souvent indiscernable, toujours indécidable dans les passages en vers par exemple.

Après tout, la clef est dans le roman. Trimalchion affirme avoir vécu «pendant quarante années comme esclave sans que personne sache s’il était réellement un esclave ou un homme libre»: annis quadraginta seruiui; nemo tamen scit utrum seruus essem an liber (sat. 57, 9). On tire de ce témoignage l'idée que les affranchis étaient bien traités, à l'égal d'hommes libres. J'en retiens tout autre chose: la difficulté d'être de ces hommes privés de toute individualité et identité propres. Ce n'est pas un habit facile à endosser que celui d'ancien quelque chose.

Le lector de Pline est ainsi ou bien un esclave particulièrement apprécié, choyé, distingué, promis à un affranchissement à une date lointaine ou bien un affranchi demeuré là où son histoire personnelle l'avait enraciné sans qu'il l'ait choisi. Sa personnalité réelle s'est révélée ailleurs que dans son rôle de lector. De conseiller culturel de son maître il en est devenu le mémorialiste clandestin. L'Histoire offre de nombreux autres exemples de secrétaires devenus les historiens de leur maître, depuis Las Cases dans le Mémorial de Sainte-Hélène jusqu'à Claude Mauriac témoin, dans le Temps Immobile ${ }^{44}$, de l'activité de Charles de Gaulle dont il était

44 Volume 5, Aimer De Gaulle, Paris, 1978. 
devenu le secrétaire particulier, à Paris, entre 1945 et $1948^{45}$. Encolpius raconte sa vie dans la maison de Pline, celle d'amis ou de connaissances. Voilà en partie le sujet initial du Satyricon, devenu sous l'effet de la puissance créatrice de leur auteur des mémoires fantasmés.

\section{Le Satyricon, un miroir de la maison de Pline le Jeune}

J'en veux pour preuve les nombreuses convergences thématiques entre la correspondance de Pline et le roman d'Encolpius. J'ai commencé tout à l'heure par la crise que connaît de son temps l'enseignement des lettres aux dires d'Encolpe. Disons pour mémoire que Pline le Jeune pensait exactement la même chose et dénonçait cette décadence en mettant en valeur le rôle des quelques intellectuels qui résistaient, parmi lesquels il comptait en bonne place son ami Titinius Capito, procurateur ab epistulis de Trajan (CIL 6, 798). Il le désignait un peu pompeusement, compte tenu de la situation désespérée dans laquelle se trouvait un monde littéraire en pleine «sénescence», comme un « rédempteur», le « réformateur» attendu: ipsarum denique litterarum iam senescentium reductor ac reformator (epist. 8, 12, I); «il est celui qui sauve les lettres aujourd'hui en déclin et les revivifie».

On écrit ensuite des épopées dans le Satyricon. Qu'elles soient miniatures, sous forme de ce que la tradition littéraire appelait des epyllia, comme par exemple les vers en hexamètres dactyliques par lesquels Agamemnon, après avoir emprunté à la tradition métrique de la satire (sat. 5, vers I-8: des choliambes), chante cette fois sur le mode héroïque le programme d'enseignement qu'il voudrait voir suivre par tous les élèves de rhétorique (sat. 5, vers 9-22), faisant au passage même l'éloge sans ambiguïté et sans aucune ironie du genre épique (vers I9: Dent epulas et bella truci memorata canore; "Que les guerres offrent l'occasion de festins littéraires, elles qui sont dignes d'être chantées sur un ton guerrier») à la composition duquel il voudrait voir les hommes de lettres se consacrer. Ou qu'elles soient de longue haleine comme les 295 vers du poème d'Eumolpe sur les guerres civiles (sat. II9-I24). Or, dans l'entourage de Pline, on écrivait l'épopée. Son correspondant Caninius

45 Cf. Claude Mauriac, Conversations avec André Gide. Extraits d'un Journal, Paris, I95I, p. 263-264, Lettre à André Gide du 4 janvier 1945: “Car il se trouva ceci: que mon ami Claude Guy sur la vie duquel je m’étais chaque jour anxieusement interrogé au cours de ces quatre années, était devenu l'aide de camp du général, et qu'il fit appel à moi, le premier soir pour l'aider, car si vite avaient été les événements que de Gaulle arrivait à Paris presque seul. C'est ainsi que je participai d'aussi près que possible aux heures historiques qui suivirent. Et que, n'ayant accepté ce poste, pour lequel je ne me trouvais point qualifié, que provisoirement et pour dépanner mon ami, je me trouve encore au Cabinet du général à ce jour, et chef de son secrétariat particulier. » 
s'apprêtait à rédiger un ouvrage sur la guerre de Trajan contre les Daces ${ }^{46}$. Il ne fait aucun doute qu'il devait s'agir d'une épopée ${ }^{47}$ et qu'elle devait être en vers grecs (epist. 8, 4, 3: graecis uersibus) imités d'Homère dont le patronage est invoqué dans ce même passage ${ }^{48}$. En outre, et c'est une conjonction remarquable avec la thématique épique dans le Satyricon, Pline lui-même a écrit des vers hérö̈ques : expertus sum me aliquando et heroo (epist. $7,4,3$ ); “je me suis jadis essayé au vers héroïque . Et puis il y a ses fameux hendécasyllabes, auxquels Pline tient tant, dont il raconte la genèse (epist. 7, 4, 3-4) et desquels il prend grand plaisir à citer un échantillon substantiel (epist. 7, 4, 6). Pourquoi n'a-t-on jamais assez insisté sur le fait que le Satyricon lui-même ne comptait pas moins de neuf passages dans ce mètre ${ }^{49}$ et que le nombre total des hendécasyllabes dont le roman est truffé se monte à 59 vers? Ajouterai-je encore à cette liste déjà nourrie? On lit en sat. 7I, I-I2 le testament rédigé par Trimalchion et en sat. I/I, 2 celui d'un autre affranchi anonyme (Eumolpe?). Or Pline autorisait ses affranchis à faire des testaments, ce qui est une libéralité notable par rapport au droit en vigueur au $\mathrm{II}^{\mathrm{e}}$ siècle $^{50}$ : permitto seruis quoque quasi testamenta facere eaque ut legitima custodio (epist. 8, r6, I); “j’autorise mes esclaves aussi à faire des espèces de testaments et je les respecte comme s'ils étaient légaux».

\section{La clémence de Pline le Jeune sujet d'une saynète dans le Satyricon}

Voici encore, par exemple, un parallèle de situation qui n’a, à ma connaissance, jamais été relevé entre les deux documents. Au début de la Cena, alors qu'Encolpe et ses compagnons sont sur le point de pénétrer dans le triclinium de leur hôte, cet espace si difficile d'accès ${ }^{51}$, ce saint des saints protégé par divers gardiens à la

46 Epist. 8, 4, I: optime facis quod bellum Dacicum scribere paras.

47 Epist. 8, 4, 3: Vna sed maxima difficultas quod haec aequare dicendo arduum, immensum etiam tuo ingenio, quamquam altissime adsurgat et amplissimis operibus increscat; "Il demeure une seule difficulté, mais d'ampleur: mettre ton discours à la hauteur de ces faits est un défi terrible, redoutable même à ton talent malgré sa capacité à atteindre les sommets et à grandir dans les travaux les plus élevés ».

48 Epist. 8, 4, 3: si datur Homero et mollia uocabula.

49 Sat. I5, 9: 2 vers; 79, 8: 5 vers; 93, 2: Io vers; Iog, I0: 7 vers; frg. 25: 4 vers; frg. 28, 9 vers; frg. 54 : Io vers; frg. $55: 5$ vers; frg. 6 r : 7 vers.

50 Cf. J. Gaudemet, Institutions de l’Antiquité, Paris, I967, p.563-564. La loi Papia Poppaea en 9 après J.-C. avait augmenté les garanties du patron en lui donnant le droit de conserver une partie de l'héritage d'un affranchi: cf. Gaius 3, 4I-42.

51 Sat. 3o, 5: cum conaremur in triclinium intrare; "tandis que nous nous efforcions de pénétrer dans la salle à manger»: le verbe d'effort marque la difficulté à parvenir jusque-là. 
manière des Champs Élysées d'un enfer sur terre ${ }^{52}$, ils sont arrêtés une nouvelle fois par la survenue inopinée d'une esclave se jetant à leurs pieds. Ce malheureux implore leur pitié et leur demande d'intercéder en sa faveur. Il a en effet commis une négligence, se laissant dérober les vêtements du trésorier qui avaient été confiés à sa garde. Encolpe et ses compagnons vont trouver le dispensator, obtiennent son pardon et se voient remerciés par l'esclave gracié. Que signifie cet épisode peu éclairé par les travaux de la critique? J'y vois pour ma part avant tout un reflet à peine déguisé de pratiques sociales du monde de Pline le Jeune. Il suffit en effet de parcourir la correspondance de ce dernier pour y reconnaître tous les motifs de la saynète du Satyricon. Simplement ce qui se passe entre homme libres chez Pline se passe entre esclaves chez Pétrone. De même que dans la comédie plautinienne le monde des serui singe celui des ingenui, ou encore l'univers des valets celui des aristocrates comme dans le chef d'œuvre de Renoir, La Règle du jeu. Pline aimait afficher sa sollicitude pour les difficultés ou les maladies de ses esclaves et c'est précisément à propos d'une indisposition d'Encolpius qu'il se déclare à l'écoute: nos solliciti (epist. 8, I, 3); “nous sommes plein d'attention ». On connaît aussi cette lettre fameuse dans laquelle Pline prétend traiter à table ses affranchis comme des convives parmi les autres, c'est-à-dire des hommes libres, leur servant notamment le même vin qu'à tous ${ }^{53}$. Le propos de Trimalchion en sat. 7I, I n'est-il pas un écho de cette protestation d'humanité: «Les esclaves aussi sont des hommes » (et serui homines sunt)? Sauf que chez Pétrone - trait d'humour en forme de clin d'œil ils boivent non le même vin que les hommes libres mais le même... lait (sat. 7I, I : aeque unum lactem biberunt)!

Le thème de l'écoute attentive prêté aux affranchis considérés comme des êtres d'une égale dignité est donc éminemment plinien: il est même mis en scène par l'épistolier qui affirme sa sollicitude dans un dialogue savamment orchestré avec un interlocuteur imaginaire ${ }^{54}$ ad maiorem gloriae sui. Le lexique même de la page du Satyricon qui nous retient est celui de Pline. Car qu'illustre la scène du roman?

52 Premier obstacle: le procurator aux comptes (sat. 3o, I); deuxième obstacle: l'esclave “superstitieux» (sat. 3o, 5); troisième obstacle: l'esclave suppliant (sat. 3o, 7). Le chien représenté sur le mur (sat. 29, I: in pariete pictus) est bien sûr un autre Cerbère.

Epist. 2, 6, 3-4.

54 Epist. 2, 6, 3-4:-Eadem omnibus pono; ad cenan enim, non ad notam inuito cunctisque rebus exaequo, quos mensa et toro aequaui.-Etiamne libertos?-Etiam; conuictores enim tunc, non libertos puto. -Et ille:Magno tibi constat. -Minime. -Quid fieri potest?-Potest quia scilicet liberti mei non idem quod ego bibunt, sed idem ego quod et liberti; «- Je sers la même chose à tous; j'invite de fait à dîner et non à un affront, et je traite à égalité en tout ceux que j'ai traité à égalité en les invitant à table. - Même les affranchis? - Oui; je les considère alors comme des convives et non des affranchis. - Lui : cela te revient cher! - Mais non. - Comment est-ce possible? - C'est possible tout simplement parce 
L'importance du pardon au sein d'une société d'affranchis, ce que leurs maîtres nomment indulgentia ou clementia. Pour ne pas alourdir mon dossier de références que l'on accroîtrait à loisir, par exemple en puisant dans le Panégyrique de Trajan, je me contenterai de citer l'entame de l'epistula ig du livre5 de Pline: Video quam molliter tuos habeas, quo simplicius tibi confitebor qua indulgentia meos tractem; “je vois avec quelle douceur tu agis avec tes affranchis; aussi vais-je te faire l'aveu en toute simplicité de l'indulgence avec laquelle j'agis envers les miens ». Ce motif, on le constate, était ainsi l'objet d'une véritable surenchère entre aristocrates. On ne saurait non plus négliger le témoignage de l'epistula i/4 du livre 8 qui montre Pline plaidant, contre les partisans de la peine de mort à l'origine majoritaires, en faveur de l'absolution pour les affranchis du consul Afranius Dexter accusés sans preuve du meurtre de leur maître ${ }^{55}$. Il est incontestable que telle fut la position de l'orateur au Sénat et qu'il fit triompher au terme de la bataille sa position ${ }^{56}$.

La différence notable avec la scène du Satyricon est la nature du délit: d'une accusation de meurtre (c'est aussi le cas dans l'affaire Larcius Macedo dans laquelle Pline prend encore une position modérée ${ }^{57}$ ) on est passé à un larcin véniel. Les habits dérobés au trésorier ne valent pas un liard ${ }^{58}$. La preuve, c'est qu'ils avaient déjà subi une fois l'épreuve du lavage qui déprécie tant les vêtements ${ }^{59}$. Le Satyricon a beau être réaliste (c'est-à-dire qu'il est inspiré par la réalité du monde plinien), il est aussi parodique (il transpose cette réalité sur un mode comique). La grandeur de Pline et sa générosité emplie de dignité pour ses affranchis est ici tournée en dérision par le moyen de l'écart entre la grandiloquence des gestes (on

que mes affranchis ne boivent pas la même chose que moi, mais c'est moi qui bois la même chose que mes affranchis ».

Epist. 8, 14, I2.

56 Epist. 8, I4, 23: obtinui quidem quod postulabam; “Oui, j'ai obtenu ce que je voulais.»

57 Epist. 3, I4. Dans le récit de cet épisode tragique du meurtre d'un maître par ses esclaves Pline fait d'une part une allusion à la cruauté de Larcius Macedo envers ses esclaves et à son désir de revanche sociale sur l'humiliation subie jadis par son père, un ancien esclave lui-même (3, I4, I: superbus alioqui dominus et saeuus et qui seruisse patrem suum parum, immo nimium meminisset; “C'était en fait un maître rempli de morgue et cruel, qui ne voulait pas se souvenir que son propre père avait été esclave, ou plutôt, qui s'en souvenait trop bien») et rappelle d'autre part la nécessité de l'humanitas ou de la “douceur» envers ses esclaves, condition nécessaire sinon suffisante (3, I4, $5:$ nec est quod quisquam possit esse securus quia sit remissus et mitis; non enim iudicio domini sed scelere perimuntur; “Il n'y a aucune raison de penser que l'on est en sécurité parce qu'on est indulgent et humain; l'assassinat des maîtres relève non d'une décision sensée mais d'un crime»).

C'est le sens de uix dans sat. 3o, 8: quae uix fuissent decem sestertiorum.

59 Sat. 3o, II : iam semel lota. 
se jette comme dans la tragédie aux pieds des grands que l'on implore: procubuit ad pedes, sat. 3o, 7) ainsi que l'emphase des discours des personnages (peccatum suum propter quod periclitaretur) et la petitesse du larcin. Ce type d'écart est un ressort bien connu de toutes les formes de comique.

Mais la parodie est encore plus fine et Pline semble bien visé. C'est ce que tendent à faire penser les concordances lexicales. L'esclave gracié couvre ses bienfaiteurs de remerciements et loue leur bonté: gratias agens humanitati nostrae (sat. 3I, 2). On pourrait songer qu'ici Encolpius prononce un discret plaidoyer pro domo, à savoir qu'il affirme l'humanité pleine et entière des affranchis qui ne sont pas des sous-hommes. Peut-être. Mais surtout on retrouve là le thème plinien de l'humanitas d'un maître modèle et empreint de bonté pour les siens. Lorsque Pline sait son affranchi Zosime souffrant, c'est son humanitas qu'il veut lui témoigner: “Même si ma nature était plus sévère et rude, je serais néanmoins touché par la maladie de mon affranchi Zosime à qui je dois d'autant plus manifester ma compassion qu'elle lui est en ce cas précis davantage utile ${ }^{60}$. „ Et même attitude de Pline, même lexique encore dans une lettre où l'épistolier s'apitoie sur les maladies de ses affranchis (epist. 8, I6, I: confecerunt me infirmitates meorum; “les maladies des miens m'ont affligé »). Il s'affirme vaincu et brisé par la compassion (humanitas) qu'il ne peut s'empêcher d'éprouver: debilitor et frangor eadem illa humanitate quae me ut hoc ipsum permitterem induxit (epist. 8, I6, 3); “je suis détruit et brisé par cette compassion-là qui m'a conduit à m'autoriser cette faiblesse même».

Le lexique de Pétrone dans l'épisode du vol des hardes du trésorier n'a aucune cohérence avec le caractère véniel de l'incident. Ce lexique est en réalité celui de Pline, ce même lexique qui traverse les panégyriques: poenas eripere (« remettre une peine»); periclitare; deprecati sumus (“on nous supplia»); remittere poenam (“adoucir un châtiment»); obligati tam grandi beneficio ("devenus ses obligés en raison d'un si grand bienfait»); gratias agens humanitati nostrae («rendant grâce à notre humanité»)... On croirait lire le De clementia de Sénèque ou encore un De officius quelconque, peut-être même le Panégyrique de Trajan. Ce lexique et ces valeurs sociales de reconnaissance liés au pardon d'une faute sont ceux d'un traité de morale, ce que les lettres de Pline, à leur manière, cherchent précisément à être.

Le trésorier dont on implore la clementia est peint avec des traits empruntés à la littérature édifiante la plus sérieuse et ses airs superbes appartiennent aux Grands qu'il singe: “Ce fat eut un mouvement de menton ${ }^{61}$. "Sa réponse pourrait passer pour celle d'un prince ou d'un patronus sinon autocrate du moins gonflé

60 Epist. 5, 19, 2: quod si essem natura asperior et durior, frangeret me tamen infirmitas liberti mei Zosimi, cui tanto maior humanitas exhibenda est quanto nunc illa magis est.

61 Sat.3o, Io: superbus ille sustulit uultum. 
de sa responsabilité et de sa dignitas: “Ce n’est pas tant la perte (des hardes) qui m'afflige que la négligence propre à un homme de rien ${ }^{62}$. „ C'est ici du grand théâtre, digne de celui que Pline mettait en scène dans ses lettres. Le motif de la iactura de grand prix si elle n'est pas réparable apparaît en effet en epist. 6, 8, 6 où il est question d'une dette que Atilius Crescens cherche à recouvrer: grauis est ei uel minima iactura quia reparare quod amiserit grauius est; “la moindre perte lui est lourde étant donné qu'il a de la peine à retrouver ce qu'il a perdu ». Là encore la parodie dans le roman pétronien réside dans l'application du motif à un objet facile à remplacer, des nippes de vil prix. Ailleurs c'est ainsi au décès d'un ami que s'applique iactura chez Pline: ‘J'ai subi une grande perte si le mot perte n’est pas trop faible pour évoquer la disparition d'un si grand homme ${ }^{63}$.»

Et puis, pour emporter définitivement la conviction - mais est-ce encore nécessaire? - citons ce billet de Pline qui raconte comment un affranchi de la maisonnée de son ami Sabinianus est venu le trouver pour implorer son pardon: “Ton affranchi, contre lequel, disais-tu, tu t'es mis en colère, est venu me trouver et s'est jeté à mes pieds comme il l'aurait fait aux vôtres et demeura prostré. Il pleura abondamment, supplia abondamment, se tut aussi longtemps et, à la fin, m'a convaincu qu'il se repentait ${ }^{64}$. » Même situation: un affranchi vient supplier l'indulgence d'un tiers et se jette à ses pieds; même lexique (sat. 3o, 7: procubuit ad pedes ac rogare coepit; Pline, epist. 9, 2I : aduolutus pedibus meis... multum rogauit).

\section{Pline le Jeune et Trimalchion: une même ambition de propriétaire terrien}

Trimalchion, enrichi dans le négoce du vin, rêve comme le fera plus tard au cinéma John Wayne, d'avoir un bien-fonds si vaste qu'il égale les frontières d'un État, voire d'un empire. Il est déjà propriétaire d'un vaste domaine, qui s'étend de Terracine à Tarente ${ }^{65}$. Ou plutôt, évoquant l'une des ses propriétés d'où provient son vin, il précise que, selon ce qu'on lui dit, elle irait ainsi du Latium à l'Italie du Sud. Tous les doctes commentateurs, de Paul Perrochat ${ }^{66}$ à Alfred Ernout ${ }^{67}$, ont vu dans ces propos de Trimalchion la preuve de son ignorance: ses connaissances en géographie seraient si faibles ou confuses qu'il ignorerait même que les territoires de

62 Ibid.: non tam iactura me mouet quam neglegentia nequissimi uiri.

63 Epist. I, I2, I: iacturam grauissimam feci si iactura dicenda est tanti uiri amissio.

64 Epist. 9, 2I, I: libertus tuus, cui suscensere te dixeras, uenit ad me aduolutusque pedibus meis tamquam tuis haesit. Fleuit multum, multum rogauit, multum etiam tacuit, in summa fecit mihifidem paenitentiae.

65 Sat. 48, 2: dicitur confine esse Tarraciniensibus et Tarentinis.

66 Pétrone. Le festin de Trimalchion. Commentaire exégétique et critique, Paris, I939, p.65.

67 Le Satiricon, cuf, p. 46. 
Terracine et de Tarente ne se touchent pas. Ainsi est née la légende (universitaire) d'un Trimalchion parvenu mais sot.

Or c'est faire là un grave contresens. Trimalchion aime à se vanter et la mégalographie qui orne les murs de son atrium n'hésite pas à le montrer chéri des dieux, promis au plus haut destin. D'ailleurs ce n'est plus un ignorant qui ajoute à peine plus bas qu'il «rêve de réunir à ses modestes propriétés la Sicile de sorte que, lorsque l'envie lui prendrait d'aller en Afrique, il pourrait naviguer à l'intérieur de ses propriétés ${ }^{68}$ ». Même un ancien esclave sait la distance qui sépare l'Italie de l'Afrique. Il n'y a là qu'exagération comique et fausse modestie dans l'emploi du diminutif agellus pour désigner «ses modestes possessions ».

Ailleurs dans le roman le même verbe iungere désigne une nouvelle fois la passion de Trimalchion pour la terre. C'est cette fois l'Apulie qu'il rêve de « réunir à ses bien-fonds » à l'occasion d'un nouvel héritage. Tel est le symbole pour lui d'une vie réussie: si je l'obtiens, dit-il, “je serai parvenu assez haut dans ma vie ${ }^{69}$ ».

Or une préoccupation identique habite de manière irritante Pline le Jeune. Navré de constater que des parcelles voisines sont enclavées dans ses propres possession, il rêve de les acquérir. Le prétexte qu'il avance ressemble à la volupté que se promet Trimalchion de se créer un empire dans l'Empire, à savoir pouvoir se déplacer et voyager tout en demeurant chez soi. La vraie raison, plus secrète, relève de l'ambition terrienne. Pline lui donne un joli nom, la pulchritudo iungendi, “le plaisir qu'il y a à s'agrandir », “l'agrandissement idéal de ses terres » ou, comme le traduit assez joliment la cuF, « le charme même de s'arrondir » : “ Ce qui me préoccupe avant tout, c'est l'idéal de l'agrandissement; puis c'est l'avantage non moins utile qu'agréable qu'offre la possibilité dans un même élan, un même déplacement, de visiter deux propriétés et de les confier au même gérant et aux mêmes agents, ou presque, d'habiter et d'embellir une première villa et de conserver simplement une autre ${ }^{70}$.

Or le verbe ici utilisé par Pline est le même que celui dont use à deux reprises, pour parler de la même passion, Trimalchion. L'auteur du Satyricon savait l'ambition de son maître pour les acquisitions foncières et la parodie gentiment à travers la même préoccupation chez son personnage, poussée en l'occurrence par grossissement comique jusqu'à la manie.

Sat. 48, 3: nunc coniungere agellis Siciliam uolo ut cum Africam libuerit ire, per meos fines nauigem.

Sat. 77, 3: quod si contigerit fundos Apuliae iungere, satis uiuus peruenero.

70 Pline, epist. 3, I9, 2: sollicitat primum ipsa pulchritudo iungendi; deinde, quod non minus utile quam uoluptuosum, posse utraque eadem opera eodem uiatico inuisere, sub eodem procuratore ac paene isdem actoribus habere, unam uillam colere et ornare, alteram tantum tueri. 
Trimalchion possède même des terres jusqu'à Baïes puisqu'il envisage un jour d'y reléguer un intendant indélicat ${ }^{71}$. Quel terme désigne ce personnage? Atriensis . Or le même mot apparaît dans la lettre où Pline avoue sa précoccupante manie de l'expansion, dans ce passage où le maître aligne les avantages financiers à posséder de grands domaines. Parmi ceux-là le fait d'avoir un seul intendant (atriensis) pour différentes propriétés constitue un gage sûr d'économies appréciables ${ }^{\mathbf{7 2}}$.

L'auteur du Satyricon baignait dans ce milieu où les questions de terre et de saine gestion ne quittaient pas les conversations de Pline (il utilise pour parler de cette préoccupation constante le verbe sollicitat). Comment Encolpius aurait-il pu ne pas songer à se servir dans son roman d'une monomanie aussi caractéristique?

\section{Le tombeau de Trimalchion: nouvelle parodie du monde de Pline}

On a déjà, pour finir, remarqué l'attention prêtée à la fois par l'auteur du Satyricon et par Pline le Jeune aux questions liées aux testaments. Il en va de même pour un aspect un peu particulier des testaments, le choix de son vivant des conditions d'inhumation dans un tombeau. Pline raconte ainsi sa tristesse à constater que le tombeau de Verginius Rufus, plus de dix ans après sa disparition en $97^{73}$, demeure inachevé. Ce qui navre Pline est que Verginius avait rédigé lui-même son inscription funéraire, laquelle rappelait qu'il avait refusé d'usurper l'empire au moment de la révolte de Vindex en 68 et qu'il cite en sa mémoire. La conclusion de l'épistolier consiste à donner le conseil à son destinataire Albinus de songer à se prémunir de son vivant de l'incurie de ses héritiers et de pourvoir lui-même à tous les soins de la construction d'un tombeau : ut ispi nobis debeamus etiam conditoria exstruere omniaque heredum officia praesumere (epist. 6, Io, 5); “aussi devons-nous nousmêmes édifier nos sépulcres et remplir par avance les devoirs de nos héritiers ». Or Trimalchion - ou Encolpius, l'auteur du roman - a entendu la leçon de Pline: non seulement il prend soin de faire connaître avant sa disparition l'épitaphe qu'il a luimême composée à sa mémoire (sat. 7I, I2), mais encore il prévoit dans le détail les modalités de construction de son futur tombeau, de la dimension du monument aux éléments d'ornement (sat. 7I, 6-7). Par souci de dérision comique le tombeau

71 Sat. 53, го: atriensis Baias relegatus.

72 Pline, epist. 3, I9, 3: inest huic computationi sumptus supellectilis, sumptus atriensium topiariorum fabrorum atque etiam uenatorii instrumenti; quae plurimum refert unum in locum conferas an in diuersa dispergas; “ Dans ce calcul, il y a le coût du mobilier, le coût des intendants, celui des concierges, celui des jardiniers, des ouvriers et enfin celui du matériel de chasse».

73 Epist.6, Io: on peut donc dater cette lettre après Io7. 
de Trimalchion sera aussi vaste (cent pieds par deux cents ${ }^{74}$ ) que celui de Verginius Rufus était modeste ${ }^{75}$.

En outre Trimalchion donne la consigne à Habinnas de s'occuper de cela dès à présent. Il le fait, dit-il, dans le but «d'éviter de subir, une fois décédé, l’infamie» (sat. 7I, 8: ne mortuus iniuriam accipiam) que constituerait un oubli de leur devoir de la part de ses héritiers, à l'instar de ce qui arriva à Verginius Rufus. Par quel mot Pline avait-il qualifié le préjudice subi par Verginius? Celui-la même dont use Trimalchion: iniuria (epist. 6, Io, 6). Le rapprochement n'est pas dû au hasard mais constitue un indice supplémentaire et sûr des relations d'influence entre les lettres de Pline et le Satyricon. Et puis Trimalchion en héritant à la mort de son maître «un patrimoine de sénateur» $(s a t .76,2)$ héritait aussi de son gentilice. Ainsi «quand il a légué sa fortune à son affranchi favori, le patron de Trimalchion a pu se dire qu'après tout celui-ci était le dernier qui perpétuât son nom et que les biens ainsi légués ne sortiraient pas du nom ${ }^{76}$ ». Paul Veyne fait ici allusion à la formule enregistrée par le Digeste $(32,94)$ par laquelle un patron lègue à ses affranchis des bien-fonds “à condition qu'ils ne sortent pas du nom ", ne de nomine suo exirent. Or Pline pose exactement la même limite au droit d'hériter qu'il accorde à ses esclaves : ils peuvent «faire des dons et des legs » dumtaxat intra domum (epist. $8, \mathrm{r} 6,2)$, «à condition que rien ne sorte de la maison ». La destinée de Trimalchion telle qu'il la raconte lui-même est donc parfaitement conforme aux pratiques recommandées par Pline.

Comment s'en étonner si Encolpius, le lector de Pline, est bien, comme l'a brillamment démontré René Martin et comme je crois l'avoir confirmé par de nouveaux rapprochements inédits et irréfutables entre la correspondance de Pline et le roman, l'auteur du Satyricon?

Dérision et parodie chez Pétrone, l'analyse n'est pas nouvelle. Ce qui l'est, c'est l'identification précise des éléments parodiés et de la cible du roman: le monde plinien. L’univers de Pline ou le microcosme de sa familia est une image en réduction de la société aristocratique romaine, de ses valeurs et de ses comportements ${ }^{77}$. Or le monde des affranchis de Pline est lui-même, aux dires de l'épistolier en personne, un état ou une ciuitas en réduction: nam seruis res publica quaedam et quasi ciuitas domus est (epist. 8, I6, 2); “car pour mes esclaves ma maison est pour ainsi dire un État et une espèce de cité». On ne saurait mieux dire. Placé au cœur de cette cité familière Encolpius, l'affranchi de Pline, son secrétaire chargé

Sat. 7I, 6: praeterea ut sint in fronte pedes centum, in agrum pedes ducenti.

Epist. 6, Io, 3: opus modicum ac exiguum.

P. Veyne, “Vie de Trimalcion» (cité note 4I), p. 23.

Cf. P. Veyne, “Vie de Trimalcion» (cité note 4I), p.6I-62. 
des affaires littéraires, l'auteur du Satyricon, en est l'observateur privilégié et le peintre amusé.

La domus de Pline le Jeune est ainsi la ciuitas de Pétrone.

\section{Deuxième partie Les Évangiles dans le Satyricon: éléments parodiques}

On a proposé dans la première partie de dater le Satyricon de la fin du règne de Trajan, après I07-III, et de situer sa composition dans la maisonnée de Pline le Jeune. Dans ce contexte la présence d'allusions aux Évangiles dans le roman non seulement n'est plus impossible mais devient vraisemblable. Cette seconde partie se propose d'examiner le dossier en tenant compte de cette nouvelle datation du roman et des conséquences importantes qui en découlent pour l'interprétation d'un ouvrage qui n'est sans doute pas l'œuvre d'un aristocrate observant de haut le monde des dépendants mais celle d'un intellectuel issu du milieu des affranchis et d'un observateur privilégié et amusé du monde aristocratique de Pline le Jeune et de son temps.

On savait Pline le Jeune préoccupé lors de son gouvernement de Bythinie par la question des chrétiens qui refusaient de sacrifier à l'empereur. On découvre ici que les Évangiles étaient connus dans son entourage proche au point de fournir à l'auteur du Satyricon l'occasion de parodies ponctuelles ou plus développées autour du motif de l'onction des pieds, de la visite au tombeau du Christ et de sa résurrection, de l'eucharistie ou même de la survie après la mort.

\section{Les chrétiens et le roman}

Si l'on en croit l'historien Ramsay MacMullen le christianisme aurait mis fin, dans l'Antiquité, au goût pour le roman. Le développement de la pensée chrétienne aurait éteint tout désir pour la fiction et le romanesque, au point, dit cet auteur, que désormais “en littérature aussi il y eut des changements notables. Rien de semblable aux romans d'Héliodore, d'Apulée ou de Pétrone ne pouvait être publié $[\ldots]$. Voilà une différence ${ }^{78}$ !». Certes R. MacMullen songe au IV siècle, lorsque

78 “There were demonstrable changes in literature, too. Nothing similar to Heliodorus', Apuleius', or Petronius' novels could be published, nor poetry like Catullus' or Ovids'. There was a difference! », “What Difference did Christianity make? », Historia 35 (3), I986, p.322-343, ici p.342, repris dans id., Changes in the Roman Empire: Essays in the Ordinary, Princeton, I99o, p. I42-I55, ici p. I54-155. - J'ai livré oralement une première version des conclusions de ce chapitre à l'occasion d'une conférence à l'université 
le christianisme se sera solidement installé. Mais, malgré tout, son affirmation demeure foncièrement inexacte: Héliodore est bien un auteur du rv siècle, postérieur au règne de Constantin, contemporain sans doute de l'Histoire Auguste, à la fin du $\mathrm{rv}^{\mathrm{e}}$ siècle, comme on le sait aujourd'hui avec une certaine dose de certitude $^{79}$. Glen W. Bowersock avait déjà signalé que «rien ne saurait être plus loin de la vérité » que l'affirmation de R. MacMullen ${ }^{80}$. De fait, si de nouveaux romans ne voyaient pas le jour, ce n'est pas en raison d'une plus faible curiosité du public pour le genre mais tout simplement parce que la fiction était désormais investie par l'hagiographie du côté chrétien et par le genre biographique du côté païen, comme l'illustre à merveille l'Histoire Auguste rédigée par le païen Nicomaque Flavien senior entre 392 et 394 .

Tout au contraire, il y eut émulation entre païens et chrétiens dans l'usage de l'arme de la fiction au service de la défense des valeurs religieuses et cette rivalité féconde connut son acmé sous le règne de Théodose ${ }^{81}$, au cours duquel saint Augustin précisément crut bon, devant la position fort ambiguë sur le sujet adoptée par saint Jérôme paraissant justifier le recours par Pierre à la dissimulation à partir d'un passage de l'Épître de Paul aux Galates (c'est la raison apparente du moins) et devant peut-être le spectacle de la multiplication des œuvres de fiction (c'est pour moi la raison réelle et profonde de l'engagement d'Augustin), de publier en 394-395 un De mendacio condamnant fermement le recours au mensonge et d'engager une polémique féroce et durable avec Jérôme sur le sujet. L'échange épistolaire des deux Pères de l'Église sur ce thème constitue en quelque sorte le premier essai de réflexion argumentée de la critique littéraire chrétienne sur l'art de la fiction ${ }^{82}$.

de Besançon. J'ai bénéficié au cours des échanges oraux et écrits qui ont suivi cette communication de nombreuses et fort utiles remarques des collègues présents que je remercie vivement: Claude Brunet, Jean-Yves Guillaumin, Michèle Ducos, Antonio Gonzalès, René Martin, Bruno Rochette et Étienne Wolff. Je dois aussi toute ma gratitude à Pierre Monat et à Christian-Bernard Amphoux qui ont répondu avec patience et une infinie érudition à toutes mes questions.

Cf. G. W. Bowersock, Le mentir-vrai dans l’Antiquité. La littérature païenne et les évangiles, I994, trad. fr. P.-E. Dauzat, Paris, 2007, p.I8I-I92, Appendice B, “Les Éthiopiques d'Héliodore; cf. en dernier lieu la confirmation de cette datation par P.-L. Malosse, “Les Éthiopiques d'Héliodore: une œuvre de l'Antiquité tardive », Revue des Études Tardo-Antiques I, 20II-2012, p. I79-I99 (en ligne) qui place, avec des arguments en partie inédits et parfaitement convaincants, le roman dans la seconde moitié du rve siècle, en tout cas après la prise de Nisibe.

80 Le mentir-vrai, p. I73.

81 Cf. St. Ratti, Polémiques entre païens et chrétiens, Paris, 2012, p.II-29.

82 La polémique entre les deux hommes a pour point de départ l'interprétation par saint Jérôme de l'Epistula Pauli ad Galatas 2-I4 (Patrologia Latina 26, col. 338-342) mais 


\section{La nouvelle datation du Satyricon: une conséquence majeure}

On sait depuis les travaux de René Martin ${ }^{83}$ que l'auteur du Satyricon ne saurait plus être identifié avec le personnage d'époque néronienne que Tacite semble avoir pris pour un “arbitre des élégances », un cognomen qui a inspiré le choix par le secrétaire de Pline, le véritable auteur du roman, de son nom de plume, Encolpius. Pour moi, en effet, ainsi que j'espère l'avoir montré plus haut, l'auteur du Satyricon connaissait bien la correspondance de Pline le Jeune, comme en avait eu jadis et partiellement l'intuition un philologue italien ${ }^{84}$. Il y a puisé un certain nombre de thèmes ou de situations caractéristiques de la vie intellectuelle du début du II $^{\mathrm{e}}$ siècle ainsi que de la condition des affranchis. Ces parallèles fournissent un argument sûr pour refuser l'identification de l'auteur du Satyricon avec le consulaire Petronius mentionné par Tacite. Ils établissent que le roman a été écrit sous le règne de Trajan et peut-être après 111, très probablement au début du $\mathrm{II}^{\mathrm{e}}$ siècle. Ils confirment enfin la thèse de René Martin qui voit en Encolpius, l'affranchi de Pline le Jeune et son lector (epist. 8, I, I-3), l'auteur du Satyricon. La première partie de cette étude apporte, je crois, de notables confirmations à cette datation et à cette identification de l'auteur du roman. Je note ici simplement en passant que l'allusion aux jardins pompéiens (sat. 53, 5) qui appartiennent à Trimalchion - dont le nom exact est d'ailleurs Pompeius Trimalchio (sat. 3o, 2) - et qui ont été victimes d'un incendie ${ }^{85}$ doivent désormais bien être mis en relation avec la destruction de la cité de Pompéi à l'automne (et non en août) de l'année 79.

Dans ce contexte, la présence d'allusions au christianisme dans le roman non seulement n'est plus impossible mais devient vraisemblable. Je me propose par conséquent d'examiner le dossier en tenant compte de cette nouvelle datation du

débouche rapidement, chez Augustin, sur une condamnation du mensonge en général: cf. Augustin, epist. 18, 3-4; 40, 3-8.

83 “Qui a (peut-être) écrit le Satyricon?", Revue des Études Latines 78, 200o, p. I39-I63; et id., Le Satyricon. Pétrone, Paris, I999. Pour une datation flavienne du Satyricon, cf. également F. Ripoll, “Le Bellum ciuile de Pétrone: une épopée flavienne? Revue des Études Anciennes I04 (I-2), 2002, p. I63-I84. Cf. récemment N. Holzberg, “Petronii Arbitri Satyricon I00-II5: Edizione critica e commento» (recension des commentaires du Satyricon par P.Habermehl, Satyrica 79-I4I: ein philologisch-literarischer Kommentar. I, Sat. 79-IIO, Berlin-New York, 2006, et G.Vannini, Petronii Arbitri Satyricon Ioo-II5: edizione critica e commento, Berlin-New York, 2010), Classical World Iо5 (2), 2012, p. 278-279: “Nowadays, however, the Satyrica is no longer dated, as Vannini seems to think, quasi unanimemente to Nero's reign; an increasing number of scholars sees the work as a product of the second century at the earliest (or at least later than Martial)».

84 L. Pepe, «Petronio conosce l'epistolario di Plinio », Giornale Italiano di Filologia II, I958, p. $289-294$.

85 Sat. 53, 5: incendium factum est in hortis Pompeianis. 
roman ${ }^{86}$ et des conséquences importantes qui en découlent pour l'interprétation d'un ouvrage qui n'est sans doute pas l'œuvre d'un aristocrate observant de haut le monde des dépendants mais celle d'un intellectuel issu du milieu des affranchis et d'un témoin privilégié et amusé du monde aristocratique de Pline le Jeune et de son temps. Ce qui change beaucoup de choses.

\section{Le tombeau de Trimalchion et le symbolisme chrétien}

La scène du testament de Trimalchion (sat. 7I, I-I2) concentre de nombreuses références à cette religion nouvelle et si étrange dont le secrétaire de Pline aux affaires culturelles, Encolpius, avait pu entendre parler autour de lui, au cours des échanges entre son maître et Tacite ${ }^{87}$ (qui mit sans doute un terme aux Annales autour de l'année i2o) ou encore, quelques années plus tôt, au moment où Pline en Bithynie demandait conseil à Trajan sur la conduite à tenir envers les chrétiens de sa province qui refuseraient de sacrifier ${ }^{88}$. Il est hautement vraisemblable, en effet, que le secrétaire du gouverneur, demeuré en Italie, ait eu connaissance des lettres en question, pour information, archivage et diffusion, comme il l'avait fait jusqu'ici pour toutes ses lettres et tous ses papiers. Quoi qu'il en soit, on en savait assez, en cette fin de $\mathrm{I}^{\mathrm{er}}$ siècle et en ce début de $\mathrm{II}^{\mathrm{e}}$ siècle, sur les chrétiens, leurs croyances bizarres, leurs textes sacrés, pour s'étonner de leur comportement et de leur originalité ainsi que l'atteste, sous Domitien, la réaction d'Épictète devant l'héroïsme dans le martyre de ceux qu'il appelle les Galiléens quand il note, dans les Entretiens $(4,7,6)$, comme l'avait relevé Ernest Renan, leur « fanatisme endurci ${ }^{89}$ ».

Trimalchion fait donc apporter au cours du banquet une copie de son testament qu'il se met à lire lui-même de bout en bout devant ses convives sincèrement navrés non tant de l'interruption des agapes mais par l'évocation de la disparition de leur bienfaiteur. Le romancier croit nécessaire de préciser que ce dernier agit oblitus nugarum (7I, 4), c'est-à-dire « sérieusement », ou mieux «blague à part ». Soit

86 Je diverge ainsi de G. G. Gamba, Petronio Arbitro e i cristiani: ipotesi per una lettura contestuale del "Satyricon», Rome, 1998 (Biblioteca di scienze religiose, I4I), dont la lecture globale et contextualisée du Satyricon postule une double intention parodique de la part de Pétrone, à la fois antichrétienne et antinéronienne. L'auteur va jusqu'à identifier Ascylte et Néron, Quartilla et Agrippine, Agamemnon et Sénèque, Trimalchion enfin et l'apôtre Pierre.

88 Epist. Io, 96.

89 “Épictète n'avait-il pas présenté l'héroïsme des “Galiléens” comme l'effet d'un fanatisme endurci? ", Marc Aurèle et la fin du monde antique, Paris, I882, p.56; cf. P. de Labriolle, La réaction païenne. Étude sur la polémique antichrétienne du $I^{e r}$ au vie siècle, Paris, 1934, rééd. 2005, p.47-5o. 
l'auteur nous informe que Trimalchion est sérieux comme l'est son testament - le croira qui veut - soit ces deux mots sont destinés à attirer l'attention du lecteur sur l'importance du morceau de bravoure qui s'annonce - ce que je crois. J'ai plus haut, dans la première partie, relevé tout ce qui dans les consignes relatives à sa sépulture données par Trimalchion à son exécuteur testamentaire Habinnas ressemble de si près à ce que raconte Pline le Jeune à propos de la tombe de Verginius Rufus (epist. 6, Io), négligée par sa propre famille après sa mort, que l'emprunt d'Encolpius dans le Satyricon à la lettre de son patron est indiscutable. On y retrouve par exemple le même souci que la sépulture ne revienne pas aux héritiers afin d'éviter qu'elle ne se dégrade à la suite de leur négligence ${ }^{90}$.

Parmi les consignes du testateur, on relève les enjolivements à donner à la future sépulture. Trimalchion demande notamment que figurent sur son tombeau des vaisseaux sculptés ou des amphores, des thèmes fréquemment attestés dans les catacombes romaines dont Giovanni Battista De Rossi a livré la description ${ }^{91}$. Il exprime également à deux reprises le vœu qu'aux pieds de sa statue soit représentée « une petite chienne», catella (7I, 6). La seconde fois cette chienne est tenue en laisse par une Fortunata statufiée (7I, II), représentée “tenant une colombe», columbam tenentem. Faut-il rappeler le symbolisme chrétien qui lie la colombe à la descente de l'Esprit saint ${ }^{92}$ et ses représentations nombreuses dans l'art paléochrétien, par exemple sur les mosaïques funéraires de Tunisie ${ }^{93}$ ? Mais, me dira-ton, la colombe se retrouve aussi dans l'art païen ${ }^{94}$. Mais quand elle est associée à la vigne - présente en abondance dans le jardinet que prévoit Trimalchion autour de sa sépulture: 7I, 7, uinearum largiter, un jardin d'Éden où abondent, dit le texte,

90 On sait que Pline le Jeune autorisait ses esclaves à tester: cf. epist. 8, I6, 2. Sur les relations ambiguës de Pline le Jeune avec ses esclaves, cf. A. Gonzalès, "Peur des affranchis impériaux et compassion envers les affranchis privés dans l'œuvre de Pline le Jeune », Fear of slaves, fear of enslavement in the ancient Mediterranean =Peur de l'esclave, peur de l'esclavage en Méditerranée ancienne (discours, représentations, pratiques), Actes du XXIX ${ }^{\mathrm{e}}$ colloque du Groupe international de recherche sur l'esclavage dans l'Antiquité (GIREA), Rethymnon, 4-7novembre 2004, éd. A. Serghidou, Besançon, 2007, p.307-324.

91 Vaisseaux: G. B. De Rossi, La Roma sotterranea cristiana, Roma, t.I, I864, pl. XXX, 5; t.II, I867, pl.XIV; Amphores : ibid., pl. XLI, 39 et 54, pl. XLIV, 39; t. III, I877, pl. XXIII, I9.

92 Matth. 3, I6; Marc I, Io.

93 Cf. J.-M. Mayeur et al., Histoire du christianisme, vol. 2, Ch. et L. Pietri et al., Naissance d'une chrétienté, Paris, I995, pl. 2I, la mosaïque funéraire de Tabarka: une colombe sur chacune des épaules du défunt.

94 Dictionnaire d'Archéologie Chrétienne et de Liturgie 3, 2, col. 2198-223I (art. "Colombe », J.-P.Kirsch, I9I4), ici col. 2203 sqq.: la colombe figure comme symbole chrétien sur les monuments funéraires les plus divers, depuis le milieu environ du II ${ }^{\mathrm{e}}$ siècle jusqu'à la fin de l'Antiquité. 
toutes sortes de pommes ${ }^{95}$ - elle peut être un gage d'immortalité, comme dans la crypte de Lucine (catacombe de saint Calixte) ${ }^{96}$, le motif même qu'évoque le héros du roman qui souhaite, grâce aux ornements de son tombeau et aux bons soins d'Habinnas, pouvoir jouir d'une vie après la mort: ut mihi contigat tuo beneficio post mortem uiuere ( $7 \mathrm{I}, 6)$. Que peut dès lors signifier cette petite chienne tenue en laisse? Deux passages des Évangiles (Matth. I5, 27 et Marc 7, 28) mentionnent les catelli, une désignation du chien domestique, enchaîné (par opposition au dogue en divagation), qui n'est pas si fréquente en latin. Il s'agit de l'épisode de la Cananéenne (mulier Chananaea) qui obtient du Christ la guérison miraculeuse de sa fille en acceptant l'idée que les bontés du Seigneur soient en priorité destinées aux chrétiens, les païens de leur côté, à la manière des chiens (catelli) sous la table, n'en recueillant que les miettes. Trimalchion veut-il signifier à sa manière que, tout païen qu'il est, il aspire légitimement lui aussi à la vie après la mort? Fortunata et son chien ne demeureront pas en reste.

\section{Trimalchion et l'onction de Béthanie}

Une autre curieuse rencontre avec les Évangiles peut être notée dans le récit d'Encolpius, au chapitre qui précède immédiatement la scène du testament. Des esclaves apportent de l'huile parfumée dont ils oignent les pieds des convives. Le texte latin mérite d'être cité:

Pudet referre quae secuntur: inaudito enim more pueri capillati attulerunt unguentum in argentea pelue pedesque recumbentium unxerunt;

"Il me fait honte de raconter ce qui suit: de fait, en vertu d'une pratique inconnue, des esclaves aux longs cheveux apportèrent une crème parfumée dans un bassin d'argent et en oignirent les pieds de ceux qui étaient attablés ${ }^{97}$.

En quoi est-ce honteux de rapporter cela (pudet)? En quoi ce traitement de faveur est-il scandaleusement nouveau? Il semble bien effet que, aux dires de Pline l'Ancien (I3, 22), M. Othon avait enseigné à l'empereur Néron comment oindre de crème parfumée la plante des pieds (mais Pline n’utilisait pas le verbe unguere,

Sat. 7I, 7: omne genus enim poma uolo sint circa cineres meos, et uinearum largiter.

Dictionnaire d'Archéologie Chrétienne et de Liturgie 3, 2, col. 23ı; G. B. De Rossi, La Roma sotterranea cristiana, Roma, I864-I877, t. I, pl. XXIII, 4 (crypte de Lucine, II $^{\mathrm{e}}$ siècle : une colombe picore une grappe de raisin); pl. XXVI, 2 (idem); t. II, pl. LV-LVI, 8; pl. LVII-LVIII, 32; t. III, pl. XIII; pl. XXX-XXXI, 7; M. Simon, Le Christianisme antique et son contexte religieux, Scripta varia, vol. 2, chapitre «Syncrétisme religieux dans l'Afrique romaine », Tübingen, I98I, p. 7og.

Sat. 70,8 . 
au demeurant rare en latin classique en dehors de quelques emplois sans rapport avec notre sujet chez Ovide, et jamais en relation ni avec caput ni avec pedes ${ }^{98}$. La nouveauté et le scandale ne s'expliquent que si la pratique est empruntée à l'attitude de la femme pécheresse qui, ayant apporté un vase d'albâtre rempli de parfum dans la maison de Simon le Pharisien, en enduit les pieds du Christ. Le récit de Luc est conforme du point de vue lexical au remploi du thème dans le Satyricon: “Tu n'as point versé d'huile sur ma tête; mais elle, elle a versé du parfum sur mes pieds "; oleo caput meum non unxisti: haec autem unguento unxit pedes meos (Luc 7, $46)^{99}$. Jean semble néanmoins le plus susceptible d'avoir servi de modèle: “C'était cette Marie qui oignit de parfum le Seigneur et qui lui essuya les pieds avec ses cheveux "; Maria autem erat quae unxit Dominum unguento et extersit pedes eius capillis suis (II, 2) ${ }^{100}$; unxit pedes Iesu $(\mathrm{I} 2,3)^{101}$.

S'il s'agit d'une coïncidence, comment expliquer dans le Satyricon l'espèce d'horreur du narrateur devant pareille pratique? Le scandale ne provient que de la tradition récente de l'humiliation de la femme devant le Christ qui lui a lavé les pieds de ses larmes et de ses cheveux et de celle du Christ lui-même s'abaissant à son tour, la veille de sa Passion, devant ses apôtres, en renouvelant ce même geste: pratique inconnue de nos mœurs romaines, dit l'auteur païen du Satyricon, inaudito more.

Un peu plus loin dans le Satyricon le motif réapparaît et c'est Trimalchion luimême qui procède à l'onction de ses hôtes :

Statim ampullam nardi aperuit omnesque nos unxit et: «Spero, inquit, futurum ut aeque me mortuum iuuet tanquam uiuum ». Nam uinum quidem in uinarium iussit infundi et: "Putate uos, ait, ad parentalia mea inuitatos esse ${ }^{102}$.»

"Il déboucha aussitôt une fiole de nard, nous en oignit tous et dit: "J'espère que cela me fera autant de bien après ma mort que de mon vivant." Il fit verser du vin dans l'urne et dit: "Imaginez-vous que vous avez été invités à mon banquet funèbre”.»

98 Pline l'Ancien I3, 22: uidimus etiam uestigia pedum tingui, quod monstrasse M. Othonem Neroni principi ferebant; “Nous avons vu que la plante même des pieds pouvait être enduite, ce qui a été enseigné, dit-on, à l'empereur Néron par M. Othon ».

99 Cf. The Greek New Testament, M. W. Holmes, Atlanta-Washington, 20Io, p. I37: ع̇ं $\alpha i \omega$

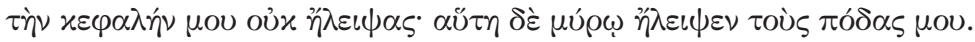

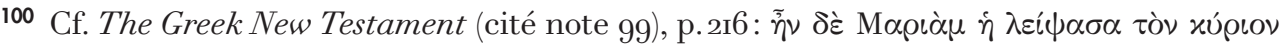

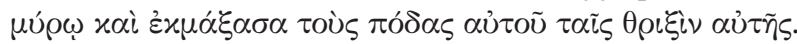

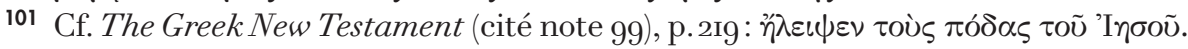

102 Sat. 78, 3. 
Trimalchion, figure parodique du Christ? Les paroles dont l'Amphitryon accompagne son geste le laissent penser : il semble bien croire à la possibilité d'une jouissance de ce bienfait après sa propre mort. Le rapprochement ici s'impose avec la scène évangélique de l'onction à Béthanie dans Marc 14, 3 :

Et cum esset Bethaniae in domo Simonis leprosi et recumberet uenit mulier habens alabastrum unguenti nardi spicati pretiosi et fracto alabastro effudit super caput eius ${ }^{103}$.

“Comme Jésus était à Béthanie, dans la maison de Simon le lépreux, une femme entra, pendant qu'il se trouvait à table. Elle tenait un vase d'albâtre, qui renfermait un parfum de nard ${ }^{104}$ de grand prix; et, ayant rompu le vase, elle répandit le parfum sur la tête de Jésus.»

Faut-il songer plutôt à Jean I2, 3 qui (outre les noms de Lazare et de Marie) mentionne l'onction des pieds et non plus de la tête: “Marie, ayant pris une livre d'un parfum de nard pur de grand prix, oignit les pieds de Jésus, et elle lui essuya les pieds avec ses cheveux»; Maria ergo accepit libram unguenti nardi pistici, pretiosi et unxit pedes Jesu et extersit pedes eius capillis suis? Si tel était le cas, Jean aurait alors inspiré Sat. 7o, 8 cité plus haut.Matthieu 26, 7 s'en tenait, de son côté, à l'onction de la tête ${ }^{105}$.

\section{Le chant du coq}

La présomption d'un lien entre le Satyricon et les Évangiles se renforce si l'on ajoute au dossier la scène du $\operatorname{coq}^{106}$ condamné par Trimalchion à la casserole parce qu'il lui semble de mauvais augure:

Sat. 74, I: Haec dicente eo gallus gallinaceus cantauit [...]. "Non sine causa, inquit, hic bucinus signum dedit; nam aut incendium oportet fiat, aut aliquis in uicinia animam abiciat! Longe a nobis! Itaque quisquis hunc indicem attulerit, corollarium accipiet».

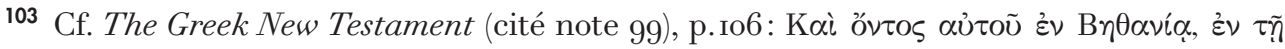

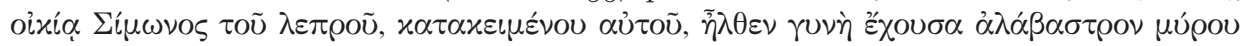

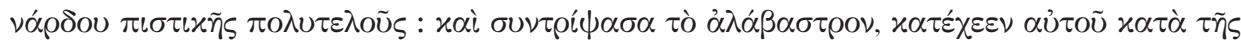
$x \varepsilon \varphi \alpha \lambda \tilde{\eta} \varsigma$.

104 Le texte grec donne $\pi \iota \sigma \tau \iota x \tilde{\eta} \varsigma$ (du nard «liquide») en place de spicati (le nard, un buisson “épineux»). Le texte latin de Jean ı2, I donne nardi pistici, du «nard pur».

105 “Une femme s'approcha de lui, tenant un vase d'albâtre, qui renfermait un parfum de grand prix; et, pendant qu'il était à table, elle répandit le parfum sur sa tête »; Accessit ad eum mulier habens alabastrum unguenti pretiosi et effudit super caput ipsius recumbentis. On relèvera qu'en Matthieu 26, 6 spicati ou pistici ont disparu.

106 Cf. I. Ramelli, “Petronio e i cristiani: allusioni al Vangelo di Marco nel Satyricon?», Aevum 70 (I), I996, p. 75-8o. 
"Tandis qu'il parlait un coq chanta [...]. "Ce n'est pas sans raison que ce joueur de trompette a lancé son signal; par le fait, ou bien il faut qu'il y ait le feu ou bien que quelqu'un rende l'âme dans les parages! Au loin! Aussi quiconque m’apportera ce délateur sera récompensé”, »

Pourquoi ce chant de l'importun animal serait-il l'annonciateur d'une catastrophe imminente, un incendie ou bien la mort d'un voisin? Rien de tel, en effet, n'est jamais associé au chant du coq dans les mentalités anciennes. Pline l'Ancien enregistre bien qu'un chant de coq poussé à des heures indues a valeur de présage, mais il est favorable ${ }^{107}$. La signification négative de la chose remonte au plus tôt aux Évangiles et à la scène du reniement de Pierre. On la lit d'abord en Marc I4, 3o, quelques pages après la scène de l'onction à Béthanie:

Marc I4, 3o: Et ait illi Iesus: Amen dico tibi quia tu hodie in nocte hac priusquam gallus uocem bis dederit ter me es negaturus ${ }^{108}$.

“ Et Jésus lui dit: “Je te le dis en vérité, toi, aujourd'hui, cette nuit même, avant que le coq chante deux fois, tu me renieras trois fois.” ’

EnLuc 22, 6o le texte latin ajoute même : Et continuo adhuc illo loquente cantauit gallus, ce qui n'est pas sans faire songer au syntagme haec dicente eo de Sat. 74, I ${ }^{109}$. La récompense promise par Trimalchion (corollarium) à quiconque rapportera le coq délateur (indicem) fait en outre penser aux trente deniers touchés par Judas pour la trahison du Christ dont parlent Matthieu (26, I5) et Marc (I4, II) quelques lignes après la scène de Béthanie. De plus, si corollarium est inconnu de la Bible ${ }^{110}$, indicem peut être rapproché de Jean II, 57: Vt si quis cognouerit ubi sit, indicet, un passage où le verbe indicet est mis dans la bouche des pharisiens à la recherche du Christ. Le coq du Satyricon connaît ainsi un dérisoire châtiment infligé par le maître queux qui, dans l'esprit parodique du romancier, tourne en dérision une scène autrement pathétique de délation.

107 Cf. Pline, nat. Io, 49. Les Béotiens se virent annoncer leur victoire sur les Lacédémoniens par des chants nocturnes répétés: habent ostenta et praeposteri eorum uespertinique cantus: namque totis noctibus canendo Boeotïs nobilem illam aduersus Lacedaemonios praesagiuere uictoriam, ita coniecta interpretatione, quoniam uicta ales illa non caneret.

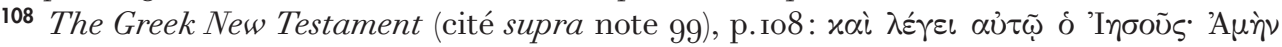

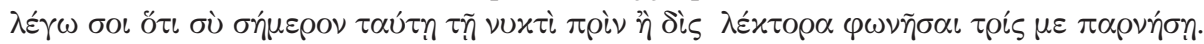

109 Je dois cette observation supplémentaire à Jean-Yves Guillaumin.

110 Mais le mot est dans la correspondance de Pline: cf. epist. 7, 24, 7. 


\section{Trimalchion croit en la vie après la mort}

Comme toujours dans le Satyricon nous avons beaucoup de difficulté à mesurer l'ampleur de la parodie et la part de la sincérité. Que l'on ne se méprenne pas, je ne crois pas une seule seconde que Pétrone-Encolpius ait écrit une œuvre réaliste et je suis certain qu'il s'est beaucoup amusé lui-même, de lui-même et des autres, de Pline et de sa maisonnée. Mais la fiction a sa part de vérité et la parodie ou le rire permettent d'aborder des sujets sérieux, en l'occurrence la mort et l'espérance d'une vie après la mort. D'ailleurs Trimalchion, comme nous, est à cet égard pétri d'une contradiction qui est de tous les temps. Il nourrit un espoir que sa simplicité d'homme sans dissimulation lui permet d'exprimer sans craindre le ridicule. Ses consignes à Habinnas sont faites pour lui assurer une vie dans son tombeau richement préparé: fais cela, lui dit-il, “de sorte qu'il m’advienne, grâce à ton aide, de vivre après ma mort ${ }^{111}$ ». Mais aussitôt la lecture du testament achevée, au chapitre suivant du roman, Trimalchion reprend ses esprits et retrouve goût à la vraie vie et invite ses amis à gagner les bains : “Et donc, puisque nous savons que nous allons mourir, pourquoi ne vivons-nous pas ${ }^{112}$ ? „Sursaut de lucidité, réflexe pragmatique, retour à la réalité ou encore autodérision à la suite d'une profession de foi quelque peu audacieuse? Un peu de tout cela sans doute.

Quoi qu'il en soit la vie après la mort espérée par Trimalchion ne semble guère chrétienne ${ }^{113}$. L'homme compte bien vivre, semble-t-il, dans son tombeau, vaste,

11 Sat. 7I, 6: ut mihi contigat tuo beneficio post mortem uiuere.

112 Sat. 72, 2: Ergo, inquit, cum sciamus nos morituros esse, quare non uiuamus?

113 La scène parodique de sat. 72, 7-Io semble plus proche de la conception virgilienne des enfers où les âmes paraissent se donner du bon temps. On sait en effet que ce passage s'inspire de Virgile, Aen. 6, 64I-645: cf. R. Martin, Le Satyricon, p.7I-72. J'ajouterai seulement ceci: la porte de sortie des Enfers qui doit nécessairement différer de la porte d'entrée (sat. 72, Io: alia intrant, alia exeunt) est aussi un souvenir parodique de Virgile, Aen. 6, 893-896; or ce passage de l'épopée proclame le caractère absolument fictif de la descente d'Énée aux Enfers: cf. P. Veyne, “Les Portes des Songes du chant VI », Virgile, L'Énéide, Paris, 2012, p.4I9-429. Rien d'étonnant, par conséquent, à ce qu'un romancier fasse ainsi un clin d'œil à un autre ouvrage d'imagination. - En outre, nemo umquam conuiuarum en sat. 72, Io (les “convives») est peut-être un jeu de mot sur uiuere. Les âmes des défunts sont bien vivantes, une étymologie pour conuiuae qu'aucun lettré ne pouvait méconnaître; cf. Cicéron, Cato I3, 45: Neque enim ipsorum conuiuiorum delectationem uoluptatibus corporis magis quam coetu amicorum et sermonibus metiebar. Bene enim maiores accubitionem epularem amicorum, quia uitae coniunctionem haberet, conuiuium nominauerunt, melius quam Graeci, qui hoc idem tum compotationem, tum concenationem uocant, ut, quod in eo genere minimum est, id maxime probare uideantur; “Même dans les banquets, c'était moins aux plaisirs gustatifs que j'attachais du prix qu'à la présence et à la conversation de mes amis. C'est avec raison que nos ancêtres ont 
riche et confortable et non dans un quelconque royaume céleste. Il fait preuve dans son épitaphe et dans la mise en scène de sa propre histoire (les vaisseaux cinglant à pleine voile représentés sur le tombeau évoquent sa carrière fulgurante de négociant ${ }^{114}$, sa générosité d'évergète est rappelée par son image de sévir augustal siégeant sur un tribunal ${ }^{115}$ ) du même orgueil satisfait que dans sa vie. Visiblement Trimalchion n'a rien compris au message évangélique ni à la question de l'âme qui ne le préoccupe pas.

Néanmoins l'attitude, le testament et les aveux de Trimalchion sur ses propres espoirs de vie après la mort me paraissent aux antipodes des convictions païennes les plus courantes telles que les livrent les épitaphes d'époque impériale par dizaines. On est très loin en l'occurrence, dans le Satyricon, de la croyance en l'anéantissement total qui devait suivre la mort et qui était si fréquemment affichée sur les tombes que les lapicides n'en gravaient que les sept lettres fameuses: NF.F.NS.NC, Non Fui, Fui, Non Sum, Non Curo ${ }^{116}$; “Je n’ai pas vécu, j’ai vécu, je ne suis plus, je m'en moque». Si l'on a pu dire Trimalchion épicurien, l'accusation ou la qualification tombe à la lecture de son testament. On voit tout ce que cet exemple peut apporter à l'encontre de la thèse curieuse de R. MacMullen qui refuse au paganisme de l'époque impériale absolument toute croyance dans l'“Afterlife», thèse exposée dans un chapitre d'un ouvrage ${ }^{117}$ où sont, à vrai dire, scrupuleusement mais tendancieusement réunis des exemples trop maigres par rapport à l'ample moisson qu'avait avant lui, avec sans doute davantage de pertinence, réunie Franz Cumont sur le même sujet dans son admirable Lux perpetua, récemment réédité de façon magistrale ${ }^{118}$. L'autocélébration de Trimalchion, sa tentative d'héroïsation de soi peuvent paraître dérisoires et sans doute ont-t-elles été voulues telles par le romancier qui n'oublie jamais qu'il est aussi parodiste, mais il demeure l'essentiel de ce que je voudrais mettre en évidence: malgré toutes

donné le nom de conuiuium au repas pris en commun avec des amis car il offre l'occasion de partager sa vie. Ce nom vaut mieux que la traduction des Grecs qui appellent cela une prise de nourriture ou de boisson en commun si bien qu'ils donnent l'impression de faire de ce qui, en l'occasion, est l'accessoire l'essentiel ».

114 Sat. 7I, 9.

115 Sat. 7I, 9.

116 Cf. e. g. CIL v, 2283 et 2893 ; pour des variantes dans les inscriptions, cf. R. Cagnat, Cours d'épigraphie latine, p.29I, et J. Carcopino, "Sur les traces de l'hermétisme africain», Aspects mystiques de la Rome païenne, Paris, I942, p. 23o.

117 Le paganisme dans l'Empire romain, trad. fr. A. Spiquel et A.Rouselle, Paris, I987, p. 97-99.

118 Lux perpetua, éd. B. Rochette et A. Motte (Bibliotheca Cumontiana; Scripta Maiora II), Torino-Turnhout, 2009. 
ses maladresse de langue (ses barbarismes: faciatur ${ }^{119}$ ) ou de tact (imposer à ses convives une mise en scène macabre), Trimalchion - et en cela il recueille toute la sympathie de l'auteur du roman - n'est pas dépourvu de toute foi en l'idée de vie après la mort. La parodie du message évangélique porte davantage sur les conditions matérielles, si je puis dire, de la réalisation de cette promesse ou de cet espoir que sur sa réalité même. Trimalchion n'est pas un philosophe et n’a jamais suivi l'enseignement d'aucun maître de cette espèce (il le fait graver dans le marbre à la troisième personne: nec umquam philosophum audiuit ${ }^{120}$. Il n'est pas un disciple de cette nouvelle philosophie et ne croit pas au Jésus des Évangiles. Mais il n’est pas pour autant en désaccord sur le fond avec son idée maîtresse d'une vie après la mort. Ne possédait-il pas chez lui trois bibliothèques, la première constituée d'ouvrages grecs, la seconde d'ouvrages latins et une troisième dont il ne précise pas la teneur $^{121}$ ? Michel Dubuisson y voyait un corpus sémitique ${ }^{\mathbf{1 2 2}}$. Trimalchion aurait-il discrètement conservé chez lui une Bible?

\section{La Matrone d'Éphèse et les Évangiles}

Les païens riaient des chrétiens mais partageaient nombre de leurs convictions ${ }^{\mathbf{1 2 3}}$. Tertullien savait déjà que les philosophes païens débattaient de la question de la survie de l'âme ${ }^{124}$. Les premiers chrétiens, en outre, au $\mathrm{II}^{\mathrm{e}}$ siècle, étaient assimilés

119 Sat.7I, I0.

120 Sat. 7I, I2.

121 Sat. 48, 4: Et ne me putes studia fastiditum, tres bybliothecas habeo, unam Graecam, alteram Latinam; ‘ Et ne va pas croire que je méprise l'étude:j'ai trois bibliothèques, la première est grecque, la seconde latine».

122 M. Dubuisson, "Aventures et aventuriers dans le Satiricon de Pétrone», Cahiers des paralittératures 5, I993, p.9-23, ici p.I6. Selon l'auteur, c'est délibérément que Pétrone occulte la teneur de cette troisième bibliothèque, masquée derrière un usage grammaticalement incorrect de altera, "seconde» bibliothèque parmi deux seulement. L'hypothèse de M. Dubuisson est reçue avec faveur par C. Brunet, «La vision de l'affranchi chez Pétrone: terminologie et discours ", La fin du statut servile? (affranchissement, libération, abolition...), $3 \mathrm{o}^{\mathrm{e}}$ colloque du Groupe international de recherches sur l'esclavage dans l'Antiquité (GIREA), Besançon, I5-16-I7 décembre 2005: hommage à Jacques Annequin, éd. A. Gonzalès, Besançon, Pufc, 2008, p. 25I-262, ici p. 259-26o. - Je remercie Bruno Rochette, Étienne Wolff et Claude Brunet d'avoir attiré mon attention sur ce point.

123 Cf. St. Ratti, Antiquus error. Les ultimes feux de la résistance païenne, Turnhout, 20Io, p. I54 et id., Polémiques entre païens et chrétiens, Paris, 2012, p. I4.

124 Cf. Apol. 47, 8: uariant; sic et de animae statu, quam alii diuinam et aeternam, alii dissolubilem contendunt; “ils ne sont pas d'accord; de même au sujet de la nature de l'âme, que les uns prétendent divine et éternelle, les autres évanescente ». 
à des espèces de philosophes par leurs détracteurs. Tertullien dans l'Apologétique se fait l'écho de ces griefs colportés par leurs adversaires qui refusaient de voir dans le christianisme « une question de révélation divine» (diuinum negotium) mais ne le considéraient que comme une « espèce de secte philosophique ${ }^{125}$ ». Parmi les reproches de ces païens vient en tête, dit Tertullien, le fait que le christianisme et les philosophes enseignent précisément les mêmes vertus.

Si l'on s'est beaucoup préoccupé de l'influence de la littérature païenne sur la nouvelle littérature d'inspiration chrétienne, l'inverse n'est pas vrai et l'on peut regretter, avec G.W.Bowersock, que la question de l'impact du christianisme sur la culture polythéiste n'ait pas été étudiée ${ }^{126}$. Les Évangiles ont-ils laissé d'autres traces dans le Satyricon? J'en vois au moins une dans le célèbre récit de la matrone d'Éphèse: Matrona quaedam Ephesi tam notae erat pudicitiae... Cela commence comme du Tite-Live... et finit dans une ambiance de vaudeville par une pointe savoureuse lorsque le peuple, ébaubi, se demande comment le défunt mari de la matrone si peu sage a pu réussir à s'aller mettre en croix ${ }^{127}$ ! Rappelons que la dame s'était enfermée avec le mort dans son caveau, “toutes issues hermétiquement closes ${ }^{128}$ ». Elle y demeure sans trouver le temps long - pour les raisons toutes personnelles que l'on sait - en tout trois jours ${ }^{129}$. Son amant n'était autre qu'un garde préposé à la surveillance du corps de suppliciés justement placés à proximité du caveau: des latrones crucifiés ${ }^{130}$. On ne peut que songer aux deux larrons, Dimas et Gestas, crucifiés, selon Marc ı5, 27 et Luc 23, 33 à côté du Christ. La veuve consolée revint donc à

125 Apol. 46, 2: Sed dum tamen unicuique manifestatur ueritas nostra, interim incrudelitas, dum de bono sectae huius obducitur, quod usui iam et de commercio innotuit, non utique diuinum negotium existimat, sed magis philosophiae genus. Eadem, inquit, et philosophi monent atque profitentur, innocentiam, iustitiam, patientiam, sobrietatem, pudicitiam; “Mais dans le même temps où notre vérité se manifeste à tout un chacun, l'incrédulité, tout en reconnaissant le bien-fondé de notre pensée [ou secte, au sens philosophique du terme], qu'elle perçoit désormais par l'expérience et par les témoignages, se refuse à y voir une affaire divine, mais y voit plutôt une espèce de philosophie. Ce sont les mêmes choses, dit-elle, qu'enseignent et professent les philosophes: l'innocence, la justice, la patience, la maîtrise de soi, la chasteté ».

126 Le mentir-vrai, p. I70, note 43.

127 Sat. II2, 8: posteroque die populus miratus est qua ratione mortuus isset in crucem.

128 Sat. I12, 3: praeclusis uidelicet conditoriiforibus. L'adverbe uidelicet n'est pas sans saveur ironique. Ailleurs on parle d'un hypogée «de façon grecque» (sat. III, 2: in hypogaeo Graeco more).

129 Sat. 12,3 : postero etiam ac tertio die.

130 Cf. sat. 111, 5: ils sont bien crucifiés (imperator prouincia latrones iussit crucibus affigi); cf. aussi 112, 8 (cruci affigi), et non pendus, contrairement à ce que peut faire penser sat. II2, 5 (pendentem). 
la vie. Comment dit-on cela en latin? Son amant utilise le verbe reuiuiscere (sat. II, I2), terme certes augustinien s'il en est, mais surtout le verbe même qui est en Luc I5, 24 dans la parabole du fils prodigue: “Car mon fils était mort, il a ressuscité: il avait péri et on l'a retrouvés (quia hic filius meus mortuus erat, et reuixit: perierat et inuentus est $)^{131}$. La renaissance toute charnelle de la veuve doit plus au vin et aux attentions du soldat qu'à un quelconque miracle, mais là réside sans doute l'intention parodique d'un romancier davantage attaché, comme ses personnages, aux biens de ce monde qu'aux promesses de l'autre.

Ainsi que l'a bien perçu G. W. Bowersock «la scène au tombeau après la crucifixion dut en vérité faire impression à bien d'autres ${ }^{132}$ ». Ce dernier a en effet mis en évidence l'influence indéniable de cette scène des Évangiles sur le roman antique, par exemple dans Sur la mort de Pérégrinus où un vieillard digne de foi, aux dires de Lucien, raconte qu'après sa mort ardente sur une bûcher funéraire d'Olympie le philosophe lui est apparu «vêtu de blanc et avec une couronne de feuilles d'olivier ${ }^{133}$ ». “L'écho des récits évangéliques est ici flagrant pour le savant anglosaxon, qui ajoute encore comme témoignage supplémentaire de la fascination exercée sur les romanciers par la scène du tombeau vide l'exemple fort probant du récit de Chariton où l'on voit Chéréas qui «arrivé au tombeau, découvrit que les pierres avaient été retirées et que l'entrée était ouverte. Il fut stupéfait de la vue et terrassé par une perplexité mâtinée d'effroi au sujet de ce qui s'était produit ${ }^{134}$.» Une réaction, dit G.W. Bowersock, à juste titre, qui n'est pas sans rappeler Marc I6, 3-5 et la stupeur des femmes devant le tombeau du Christ vide. L'influence des Évangiles sur le roman de Chariton est d'autant moins invraisemblable que l'on

131 Cf. aussi Luc I5, 32 : frater tuus hic mortuus erat et reuixit.

132 Le mentir-vrai, p. I44-145.

133 Lucien, Sur la mort de Pérégrinus 40.

134 Chéréas et Callirhoé3, 3, I-2, cité par G. W. Bowersock, Le mentir-vrai, p. I45. Pour d'autres exemples de motifs chrétiens comme la crucifixion, la résurrection ou la $\tau u \mu \beta \omega \rho u \chi i \alpha$ (l'intrusion de voleurs dans un tombeau) chez Chariton, cf. I. L.E. Ramelli, “The ancient novels and the New Testament: possible contacts ", Ancient Narrative 5, 2007, p.4I-68. - On peut hésiter à faire figurer dans ce dossier l'interprétation controversée de sat. 62: Ma(c)ta uita tau dans la scène du loup-garou. Le texte, loin d'être sûr, a fait l'objet de plusieurs tentatives d'élucidation. R.Blümel, “Mata vita Tau bei Petronius 62», Philologus, I927, p.47I-472, y a lu des impératifs suivis d'une interjection, auquel cas je comprendrais ainsi cette espèce de formule d'encouragement: «Bats-toi, en garde, par la croix!» ou encore: “Tue, esquive, par la croix!». Relevons simplement encore que pour Th.E.Schmidt, “The letter tau as the Cross: ornament and content in Hebrews 2, I4", Biblica 76 (I), I995, p. 75-84, une allitération en t (tau) dans ce passage du Nouveau Testament serait une allusion au Christ. Rien ne prouve néanmoins un lien indubitable entre le tau de la formule du Satyricon et la croix du Christ. 
pense désormais pouvoir placer la rédaction de ce dernier dans la première moitié du $\mathrm{II}^{\mathrm{e}}$ siècle ${ }^{135}$, peut-être entre $\mathrm{I} 3 \mathrm{o}$ et $\mathrm{I} 4 \mathrm{O}$, soit entre vingt et trente ans à peine après le Satyricon.

“Mangez mon corps»: une scène d'eucharistie dans le Satyricon

Le plus curieux des passages recelant sans doute une parodie des croyances chrétiennes figure dans le Satyricon à un endroit peu remarqué, dans les fragments que l'on ne peut rattacher aisément à la trame du roman. Il s'agit pourtant là encore d'une scène de testament, et pas n'importe laquelle. Eumolpe lit semble-t-il luimême les conditions qu'il met à son propre testament, portant en l'occurrence sur une “immense fortune» (pecuniae ingens fama ${ }^{\mathbf{1 3 6}}$ ). Il s'agit de faire découper son corps en morceaux et de le manger:

Omnes qui in testamento meo legata habent, praeter libertos meos hac condicione percipient quae dedi, si corpus meum in partes conciderint et astante populo comederint;

“Tous ceux qui bénéficient de legs dans mon testament - sauf mes affranchis - ne percevront ce que j'ai donné qu'à la seule condition qu'ils découpent mon corps en morceaux et le mangent devant le peuple debout ${ }^{137}$. »

Curieuse cérémonie de laquelle G. W. Bowersock a naguère rapproché le déroulement des Évangiles narrant la Cène, un repas au cours duquel le Christ invite ses disciples à partager son sang et son corps en consommant du vin et du pain $^{138}$. On aurait donc là une parodie de l'eucharistie.

Cette signification parodique est d'autant plus sûre qu'elle se double d'un jeu de mot assez limpide. Eumolpe (ou l'un de ses compagnons après la mort d'Eumolpe) lit son testamentum, d'un genre absolument nouveau et inédit dans ses prescriptions (malgré le rapprochement possible avec Hérodote 3, 99), ce nouum testamentum n'est autre que la transcription de la “Nouvelle Alliance» (Kainè Diathêkê) des Évangiles, le mot grec diathêkê signifiant pour tout grec du i ${ }^{\mathrm{er}}$ siècle "testament» et non “alliance». L'auteur du Satyricon a entendu diathêkê comme ceux qui parlaient grec aux temps de Jésus et comme ses contemporains; il a donc enregistré testamentum, comme le feront les traducteurs modernes de la Bible. Le testament inouï d'Eumolpe parodie le Nouveau Testament chrétien.

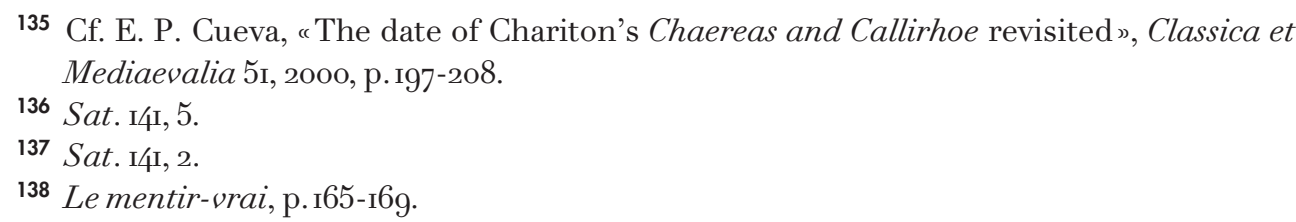


Allons plus loin que ne l'avait fait G.W.Bowersock que je viens de résumer. Le peuple assemblé (astante populo), devant lequel ceux qui espèrent l'héritage d'Eumolpe devront manger son corps, ressemble furieusement à une réunion, une église (ecclésia) de fidèles chrétiens ${ }^{139}$. Visiblement le repas fait de chair humaine constitue dans l'esprit d'Eumolpe une punition destinée à châtier les captateurs d'héritage pour leur cupidité et leur ingratitude. Ils ont été insultants pour le défunt et cette épreuve est conçue pour leur faire payer leur attitude passée:

His admoneo amicos meos ne recusent quae iubeo, sed quibus animis deuouerint spiritum meum, eisdem etiam corpus consumant;

«J'engage mes amis à ne pas se dérober devant mes ordres, mais au contraire à mettre la même ardeur que celle qu'ils eurent à dévouer mon âme aux dieux infernaux à manger aussi mon corps ${ }^{140}$.

Le seul texte qui fait ici sens est bien deuouerint, «maudire», et non deuorarint comme on a pu le proposer en affaiblissant et dénaturant même le texte original ${ }^{141}$. L'opposition entre spiritus et corpus est décisive: elle reflète l'opposition entre pneuma et sarx dans les Évangiles ${ }^{142}$, comme l'a bien vu G. W. Bowersock ${ }^{143}$.

\section{Manger de la chair humaine: une punition réservée aux aristocrates cupides}

Mais on peut aller plus loin. Eumolpe exclut de ses prescriptions ses affranchis, plutôt il les en dispense. La punition n'est destinée qu'aux hommes libres, à ces aristocrates cupides dont Pline (et Tacite) ne cesse de nous raconter qu'ils sont prêts à tout pour engranger les héritages. Les liberti d'Eumolpe ne sont pas soumis à la punition ni accusés: n'oublions pas que l'auteur du Satyricon a pour les esclaves et les affranchis de ces prévenances qui dénotent, au-delà des brocards toujours bon enfant dont il les charge souvent, une vraie affection qui ne s'explique que par sa communauté d'origine avec eux. Encolpius, le lector de Pline et l'auteur du Satyricon, est un libertus et il ne l'oublie jamais dans l'échafaudage fort équilibré de ses attaques, moins féroces qu'on ne le croit parfois. La cible du Satyricon, on le sait désormais, est davantage l'aristocratie et le monde de Pline le Jeune que la valetaille, le monde des esclaves et des affranchis. Il faut s'habituer à

139 Marc I4, 70: rursus qui astabant dicebant Petro; Luc 19, 24: Et astantibus dixit; Act. 23, 2 : praecepit astantibus; Act. 23, 4: et qui astabant dixerunt etc.

140 Sat. I4I, 4.

141 G. B. Conte, “Petronius, Sat. I4I, 4», Classical Quarterly 37, I987, p.529-532.

142 Matth. 26, 4I;Marc I4, 38.

143 Le mentir-vrai, p. 169 
cette révolution copernicienne qui inverse le point de vue exprimé dans le roman et qui doit modifier dans la même proportion notre lecture.

Ce qui demeure, c'est le sel d'une charge transparente contre les chrétiens et l'eucharistie, un rite qui avait nourri les rumeurs par son caractère absolument inédit et scandaleux ${ }^{144}$. Comment ces derniers pouvaient-ils accepter l'idée répugnante de manger de la chair humaine? La réponse est donnée par l'auteur du Satyricon: il n'est pire supplice qui ne puisse être enduré pour de solides et basses raisons pécuniaires. D'où l'image du testament, si chère à ces mêmes chrétiens. Ce qu'Eumolpe dit (de son vivant, en lisant son testament, ou après sa mort si le testament est lu par un tiers, il est difficile de trancher en l'état du texte) à ses amis hésitant à s'exécuter vaut pour les chrétiens :

De stomachi tui recusatione non habeo quod timeam. Sequetur imperium si promiseris illi pro unius horae fastidio multorum bonorum pensationem. Operi modo oculos et finge te non humana uiscera, sed centies sestertium comesse;

“Quant à la répugnance qui est celle de ton estomac, je n’ai aucune crainte. Il suivra tes instructions si seulement tu lui promets en échange d'une seule petite heure de dégoût la compensation de nombreuses récompenses. Il te suffit de fermer les yeux et de te figurer que tu ne manges pas de la chair humaine mais que tu avales un bon million de sesterces ${ }^{145}$. $)$

On ne saurait être plus désobligeant pour la communion et les motivations des chrétiens procédant à l'eucharistie. Le parallèle qui suit dans le même fragment du roman avec les Sagontins dévorant de la chair humaine ou les femmes de Numance qui, lors du siège de la cité, ont été retrouvées tenant sur leur sein le corps de leurs enfants à demi dévorés ne sont guère plus sympathiques ${ }^{146}$. L'art qui sait accommoder les plats (blandimenta; ars: sat. I4I, 8) ressemble fort aux blandices de la rhétorique chrétienne.

144 Cf. Pline, epist. Io, 96, 7: ad capiendum cibum promiscuum tamen et innoxium; les chrétiens se réunissent "pour prendre leur nourriture qui est commune, quoi que l'on dise, et innocente ». Pline le Jeune était donc informé des bruits qui circulaient sur la nature de cette nourriture. Cf. aussi Eusèbe, Histoire ecclésiastique 5, I, 52; au cours de son supplice, sur le bûcher, Attale dit: «Voyez, ce que vous faites, c'est manger des hommes. Pour nous, nous ne mangeons pas des hommes et nous ne faisons rien d'autre de mauvais ».

145 Sat. I4I, 6-7.

146 Sat. I4I, 9 et II. 


\section{L’immortalité par les ouvres}

Mais quelles sont les promesses faites aux chrétiens et les millions que leur religion leur fait miroiter s'ils accomplissent le geste que le Christ a demandé à ses disciples? La réponse se trouve non pas dans le Satyricon mais dans une lettre de Pline le Jeune que l'on n'a jamais, à ma connaissance, interprétée comme je le propose à présent.

Cette lettre à Novius Maximus ressemble, comme souvent chez Pline, à un éloge: C.Fannius vient de mourir et l'épistolier paraît à première lecture rédiger sa notice nécrologique. Fannius était historien: il avait publié trois livres critiques sur le règne de Néron et laisse à sa disparition l'ouvrage inachevé. Mais que lit-on derrière les compliments d'usage adressés à la mémoire d'un érudit fort éloquent? Il est mort dans des conditions qui navrent Pline et qui sont l'objet d'un premier reproche: il est mort en laissant un curieux testament. Ce texte prévoit en effet, ce qui désole Pline (angit me), que ses amis ou parents les plus chers seront déshérités au profit de ses ennemis, largement dotés : omisit quos maxime diligebat, prosecutus est quibus offensior erat (epist. 5, 5, 2). Une curieuse pratique, à l'encontre de tous les usages et de toutes les idées de Pline lui-même sur la question. Ce testament est dit dans le texte latin ueteri testamento, ce qui a peut-être une connotation antichrétienne quand on se souvient du testament nouveau d'Eumolpe. Et puis, n'est-ce pas une générosité toute chrétienne que celle qui consiste à pardonner ses ennemis et à les privilégier dans son affection au détriment des amis avérés? Le second reproche explicite formulé par Pline à la mémoire de son ami disparu est d'avoir laissé inachevé son ouvrage historique. Non pas tant parce que le contenu hostile à Néron prive ses lecteurs d'un pamphlet politique parmi d'autres, mais plutôt parce que cette mort prématurée ôte à l'historien toute perspective d'immortalité: mihi autem uidetur acerba semper et immatura mors eorum qui immortale aliquid parant (epist. 5, 5, 4); “je trouve toujours particulièrement douloureuse et précoce la mort de ceux qui travaillent à l'immortalité». Autrement dit l'immortalité ne s'acquiert que par les œuvres (et non par la foi) et Fannius a manqué la sienne en laissant son travail interrompu. Ses efforts, dans cette quête de survie, ont été vains : “Combien il a dépensé d'énergie pour rien ${ }^{147}$ !

La leçon à tirer de l'échec de Fannius dans sa quête spirituelle est claire pour Pline: sa propre condition de mortel (epist. 5, 5, 7: mea mortalitas) ne peut être dépassée que par le travail, ses propres écrits garantissant sa postérité (mea scripta). La mort n'est qu'un anéantissement, sans espoir de survie de la moindre parcelle d'âme et seules les œuvres peuvent prétendre à échapper à cette abolition du souvenir: “Aussi, tant que la vie est là, efforçons-nous à ce que la mort ne

147 Epist. 5, 5, 7:quantum laboris exhauserit frustra. 
trouve que le moins possible à détruire ${ }^{148}$. „ Non seulement Pline n'est pas chrétien pour un sou dans ses affirmations, mais encore il semble bien reprocher à travers l'exemple de son ami Fannius, l'historien sans avenir, à la nouvelle mentalité chrétienne telle qu'elle s'exprime dans l'Ancien Testament, ou Alliance passée avec son dieu, d'inverser les priorités. Un bon testament privilégie ses vrais amis comme un bon intellectuel pourvoie lui-même à son immortalité par ses œuvres et non par des convictions éthérées. L'état d'esprit de Pline, on le voit, n'est guère éloigné de celui de son lector auteur du Satyricon et la lettre sur Fannius doit être ajoutée à l'ensemble des références que j’ai réunies en faveur de l'idée que notre Encolpius était familier de la correspondance de son maître.

\section{Le Satyricon et la datation des Évangiles}

La datation nouvelle du Satyricon que je défends - au début du II ${ }^{\mathrm{e}}$ siècle, vers Io7-III, à l'époque peut-être où Pline le Jeune part pour la Bithynie - rend tout ce que j'ai écrit ci-dessus parfaitement vraisemblable et corrobore l'intuition naguère exposée avec prudence par G. W. Bowersock : le Satyricon «présageait de l'impact que les récits des évangélistes devaient avoir sur l'imagination des écrivains et des lecteurs dans le monde gréco-romain au cours des siècles à venir ${ }^{149}$ ). Sauf que ce roman ne date pas, comme le croit le savant anglo-saxon, du règne de Néron. G. W. Bowersock était passablement embarrassé par les conséquences de ses observations qui ne coïncidaient pas avec la chronologie. Il est certes vraisemblable qu'en 65, date supposée de la mort du consulaire Pétrone mentionné par Tacite, “les tout premiers Évangiles existant aient été en cours d'écriture ${ }^{150}$ » (la formulation “ en cours d'écriture » révèle la gêne de l'auteur, fort bien informé par ailleurs sur le sujet) ou, en tout cas, qu'un romancier païen ait pu à cette date en avoir eu connaissance. Mais le plus ancien sans doute des Évangiles, Marc, ne date qu'au plus tôt des environs de l'année 7o, en raison des brèves allusions qu'il contient à la destruction du Temple de Jérusalem ${ }^{151}$. Matthieu, pour la même raison, est postérieur sans doute à 7o et date sans doute des environs de l'année $8 \mathrm{o}^{152}$, même si la controverse demeure ouverte, la fourchette communément retenue étant les années 6o-85. Néanmoins, comme me l'écrit Christian-Bernard

148 Pline, epist. 5, 5, 8: proinde dum suppetit uita, enitamur ut mors quam paucissima quae abolere possit inueniat.

149 Le mentir-vrai, p. 169

150 Le mentir-vrai, p. 149 .

151 O. Cullmann, Le Nouveau Testament, Paris, I966, p.34.

152 Allusion possible à la première révolte juive et à la destruction du Temple en Matth. 22, 7; cf. O. Cullmann, Le Nouveau Testament, p. 29. 
Amphoux, “dans les années 3o-6o, il existe une collection de paroles de Jésus qui prend des formes successives, dont il nous reste trois états: les sections de paroles de Matthieu, la collection centrale de Luc et l'Évangile selon Thomas » et «avant 7o, un premier livret de Marc est rédigé à Rome et amplifié à Alexandrie; le livret romain est repris et transformé par Luc, tout cela avant la fin de la guerre contre Rome. Dans le livre de Luc, le dernier repas de Jésus forme un épisode ${ }^{153}$ ». On peut donc, avec Christian Amphoux, penser qu'“en III, la rédaction finale des Évangiles (édition de I20-I3o) n'existe pas encore, mais les sources des Évangiles existent déjà, même si elles ne sont pas encore réunies ${ }^{154}$ ».

Demeure cependant une question difficile et que je ne saurais trancher ici: l'auteur du Satyricon a-t-il consulté une traduction latine des Évangiles grecs ou s'est-il contenté de reproduire, en les parodiant, les bribes de récit oraux, extraits en grec ou anecdotes plus ou moins bienveillantes, qui ne devaient pas manquer de circuler en nombre sur les croyances des chrétiens autour de l'année iII, comme l'atteste Pline le Jeune? Il semble en effet délicat d'affirmer que les Évangiles, tels que nous les a conservés la Vetus Latina, aient déjà été traduits en latin à cette date, la plupart des spécialistes préférant faire de Tertullien, avant saint Cyprien, puis Lucifer de Cagliari, le premier témoin de la “Vieille Latine ${ }^{155}$ ». Ou alors le Satyricon et ses emprunts seraient les premiers témoins de l'existence de ces traductions dans la première moitié du II siècle. Mais le recours par l'auteur du Satyricon à un grec partiel des Évangiles suffit à soutenir la thèse d'une parodie.

Le Satyricon, vers Io7-III, ne “présage» donc pas de l'influence des Évangiles sur la littérature de fiction: il l'enregistre et la révèle. Il est même chronologiquement le premier témoin de cette influence, ceci dit pour rendre hommage au génie de son auteur qui allait lancer une mode dont Chariton et d'autres, par exemple

153 Lettre de septembre 20I2. - J'exprime à Christian-Bernard Amphoux toute ma gratitude pour m'avoir éclairé de sa science immense sur ce sujet.

154 Cf. Ch.-B. Amphoux, "Quelques remarques sur la formation, le genre littéraire et la composition de l'Évangile de Marc », Filologia neotestamentaria 19-20, 1997, p.5-34 et, $i d$., “Le canon du Nouveau Testament avant le Iv siècle », Filologia neotestamentaria 2I, 20o8, p. 9-26.

155 La thèse ancienne de P.-L. Couchoud, “L'Évangile de Marc a-t-il été écrit en latin?» Revue de l'histoire des religions 94, I926, p. I6I-I92, qui croyait à l'existence d'un Marc latin ne semble plus devoir être retenue. - Je remercie vivement Pierre Monat de ses remarques érudites sur cette question complexe; sur les Évangiles, cf. son ouvrage, Histoire profane de la Bible. Origines, transmission et rayonnement du Livre saint, Paris, 20I3, p. 79-89. 
Apulée ou Achille Tatius, allaient s'inspirer et se faire à leur tour, mais plus tard, les brillants illustrateurs ${ }^{156}$.

\section{Nicomaque Flavien senior, Pétrone et les pseudonymes}

J'aimerais enfin clore mes remarques par une réflexion sur l'Histoire Auguste. J'ai, il y a peu, avancé des arguments totalement inédits en faveur de l'idée que Nicomaque Flavien senior avait lu le Satyricon: je les ai trouvés dans le Polycraticus de Jean de Salisbury qui indique sans aucune ambiguïté que Flavien connaissait le récit de la Matrone d'Éphèse et qu'il s'en était bien amusé ${ }^{157}$. L'auteur de l'Histoire Auguste avait même trouvé dans le Satyricon le nom d'Encolpius dont son imagination a fait un biographe de l'empereur Alexandre Sévère ${ }^{158}$. On sait en effet l'extrême rareté de ce nom qui n'apparaît jamais ailleurs dans la littérature conservée que chez le pseudo-Pétrone, chez Pline le Jeune et dans la Vita Alexandri de l'Histoire Auguste. Quelles raisons avaient bien pu pousser la curiosité infatigable de cet intellectuel païen à s'intéresser à cet ouvrage si peu académique? Le fait même que l'ouvrage n'était pas académique, pas plus que l'Histoire Auguste, qu'il avait été édité sous un pseudonyme, comme l'Histoire Auguste, qu'il était un chef d'œuvre d'humour et de parodies littéraires ${ }^{159}$, comme l'Histoire Auguste, et qu'enfin, comme l'Histoire Auguste, il disait du mal des pratiques inconcevables mises à la mode par la nouvelle religion. Faut-il trouver d'autres explications?

Le goût des hommes de lettres qui ont quelque fantaisie pour l'art si délicat du travestissement littéraire est de toutes les époques. Les Romains ne riaient pas moins que nous, et souvent des mêmes choses.

Nicomaque Flavien prit six pseudonymes différents pour démultiplier encore si possible l'effet comique de son œuvre-testament, l'Histoire Auguste. Je ne connais pas meilleure explication de cette prolifération des masques que celle que fournit à son propre endroit un écrivain qui savait de quoi il parlait en matière de mystification et de dissimulation d'identité littéraire, Roman Kacew, le vainqueur

156 Pour une analyse de la communauté axiologique entre les romans grecs et le christianisme, cf. I. Ramelli, “Les vertus de la chasteté et de la piété dans les romans grecs et les vertus des chrétiens: le cas d'Achille Tatius et d'Héliodore», Passions, vertus et vices dans l'ancien roman, Actes du colloque de Tours, I9-2I octobre 2006, éd. B. Pouderon et C. Bost-Pouderon, Paris, 2009, p. I49-168.

157 Cf. St. Ratti, Polémiques entre païens et chrétiens, Paris, 2012, p. I4I-I45.

158 Histoire Auguste, Alex. I7, I ; 48, 7.

159 Eumolpe, au moment de réciter son poème sur "La Guerre civile», prévient ses auditeurs: Ecce belli ciuilis ingens opus: quisquis attigerit nisi plenus litteris sub onere labetur; “Voici à présent mon œuvre majeure sur la Guerre civile: quiconque l'abordera sans une culture littéraire solide succombera sous le fardeau » (sat. Iı8, 6). 
de deux prix Goncourt sous ses deux hypostases Romain Gary et Émile Ajar. Dans son roman La Promesse de l'Aube, Romain Gary raconte que dès son enfance il se rêvait écrivain. Il n'envisageait pas de le devenir sans se choisir un pseudonyme et passait des heures entières, dit-il, à les essayer: “Je les calligraphiais à l'encre rouge dans un cahier spécial ${ }^{160}$.» La prolifération masque l'insatisfaction car le jeune Romain a trop à dire pour qu'un seul nom de plume renferme l'ensemble de ses vastes projets. Le pseudonyme est par essence pluriel, puisque la perte de l'identité s'accompagne volontiers d'une reconstruction inauthentique multiple. Perdre une fois son nom efface tout scrupule dans l'adoption de patronymes de substitution toujours différents.

Dans la spirale de la mythistoriographie (dans le cas de l'Histoire Auguste) ou dans celle de l'imposture plus mondaine (dans celui du Satyricon) la dérive de la surenchère guette à tout moment l'auteur prisonnier de ses propres mensonges. On tient là, je crois, l'une des explications possibles de l'accroissement en volume d'œuvres aussi différentes que l'Histoire Auguste et le Satyricon mais qui, toutes deux, sont de longueur respectable (je rappelle que nous ne possédons avec le Satyricon qu'environ le cinquième du roman original perdu). Le mensonge s'accroît de lui-même plus aisément que la vérité et l'auteur masqué a toute liberté de ne rien craindre de ses contradictions.

L'auteur de La Promesse de l'aube l'avait bien compris, lui qui écrivait: ‘L'ennui avec un pseudonyme, c'est qu'il ne peut jamais exprimer tout ce que vous sentez en vous. J'en arrivais presque à conclure qu'un pseudonyme ne suffisait pas, comme moyen d'expression littéraire, et qu'il fallait encore écrire des livres ${ }^{161}$.»

\section{Le paradigme Émile Ajar}

Romain Gary a donné une explication limpide de son goût pour le pseudonyme. L'écriture dans ces conditions lui offrait des formes de “prolongements» à sa propre personne, trop étriquée, prisonnière d'un “monde rétréci ${ }^{162}$ ». Comme a dû le vivre l'auteur de l'Histoire Auguste on doit imaginer sous chaque hypostase du romancier un être nouveau. Gary revit: ‘Jusqu’à, ajoute-t-il, ce que la création littéraire devînt pour moi ce qu'elle est toujours, à ses grands moments d'authenticité, une feinte pour tenter d'échapper à l'intorélable, une façon de rendre l'âme pour demeurer vivant ${ }^{163}$.» Rendre l'âme pour mieux revivre, on reconnaît ici le thème central d'un autre roman de Gary, Charge d'âme.

\footnotetext{
160 La Promesse de l’Aube, Paris, I96o (édition définitive i980), p. 24.

161 Loc. cit.

162 La Promesse de l'Aube, p. 175 .

163 Loc. cit.
} 
Quant à la feinte (gage d'authenticité), on sait qu'elle fut l'attitude constante de l'homme Nicomaque Flavien dont le parent Symmaque relevait que nul, à part lui, ne savait pénétrer les secrets. En fait Flavien, en lutte contre le pouvoir autoritaire du très chrétien Théodose, masquait ses convictions religieuses secrètes, antichrétiennes, dissimulées dans son for intérieur, son temple intime, son penetral sacré. Il les avait à peine révélées dans l'Histoire Auguste, rédigée sous des masques assez transparents pour que sa vanité d'écrivain n'ait pas à souffrir d'écrire anonymement, mais assez opaques pour tromper la balourdise de la police théodosienne ${ }^{164}$.

La question que l'on me pose souvent est en effet celle-ci: comment une œuvre aussi grossière que l'Histoire Auguste a-t-elle pu tromper son monde? Il est tout aussi légitime de se la poser à propos du Satyricon: comment une fiction aussi vulgaire a-t-elle pu être composée dans la propre maison d'un aristocrate aussi raffiné que Pline le Jeune?

La première réponse qu'il convient de faire est que ni Flavien ni Encolpius n'ont peut-être trompé personne parmi leurs contemporains et leurs proches (l'aveuglement, dans les âges modernes de la philologie, de générations de lecteurs savants s'explique par le temps écoulé - plus de dix ou treize siècles avant les premières éditions humanistes - et l'oubli). Leur entourage a bien pu être complice, activement ou passivement. On a vu que Symmaque savait son parent Flavien adepte des cachoteries et autres dissimulations diplomatiques. Pline, de son côté, aimait la plaisanterie et avait l'esprit libéral.

La seconde réponse est plus amusante: ni Théodose (ou son entourage) ni Pline (et sa familia) n'ont peut-être trouvé en eux la lucidité nécessaire pour percer l'énigme. Non pas que l'intelligence des hommes et des situations leur ait fait défaut (au contraire), mais justement parce que leurs cadres habituels de pensée, ceux qui étaient en vigueur dans l'administration impériale à la fin du rv siècle ou dans les milieux sénatoriaux de l'époque de Trajan, n'offraient rien de comparable ni aucun modèle satisfaisant d'explication. On n'écrivait de fiction romanesque ni à Constantinople à la cour de l'empereur chrétien, ni dans les rangs de l'austère ordo où brillait alors la figure tutélaire du sévère Tacite.

Pour tout dire, des forgeries comme le Satyricon ou l'Histoire Auguste étaient pour les contemporains, même lettrés, de Flavien et de Pline le Jeune des ovnis littéraires.

Nos deux hommes étaient comme enfermés dans l'image que leur vie publique offrait d'eux depuis des décennies. Flavien avait servi divers Princes depuis un quart de siècle quand il met la dernière main, avant sa mort en 394, à l'Histoire

164 Cf. St. Ratti, “Nicomaque Flavien démasqué», Antiquus error. Les ultimes feux de la résistance païenne (Bibliothèque de l'Antiquité Tardive, I4), préf. J.-M. Carrié, Turnhout, 20I0, p. 26I-270; id., Polémiques entre païens et chrétiens, Paris, 20I2, p. II-29. 
Auguste. Encolpius était le secrétaire aux affaires culturelles de Pline, un lector modèle, vanté par son maître à ses amis. Encore une fois, c'est Romain Gary qui fournit le modèle interprétatif le plus pertinent. Dans Vie et mort d'Émile Ajar il raconte les vicissitudes de ses transformations auctoriales, de pseudonymes en prête-noms (et prête-visage). Écrit peu avant son suicide, ce récit, daté du 2ı mars I979, se termine sur le célèbre et pathétique: ‘Je me suis bien amusé. Au revoir et $\operatorname{merci}^{165}$.

Gary y raconte que personne jamais ne s'est avisé que lui-même et Ajar ne faisaient qu'un. Et ce malgré les nombreuses et voyantes preuves du contraire. À commencer par la conclusion de l'enquête d'une journaliste du magazine Match qui avait tout compris, repérant notamment que le refrain (à tonalité humoristique) «Je m'attache très facilement» revenait aussi bien dans La Promesse de l’Aube (signée Gary) que dans Gros Câlin (signé Ajar) ${ }^{166}$. En outre Gary, qui n'avait pas encore consciemment décidé de publier Gros Câlin sous un pseudonyme, en laissait le manuscrit en cours ouvert sur sa table de travail, où purent le voir ses visiteurs, par exemple cette Madame Lynda Noël ${ }^{167}$.

L'inimaginable est que personne ne crut jamais ni ces témoins, ni les enquêteurs qui repérèrent les points communs entre les ouvrages d'Ajar et de Gary et les tournures stylistiques récurrentes. Rien n’y fit: Gary restait prisonnier «de la gueule qu'on lui avait faite» et il demeurait «impensable» que l'écrivain en fin de parcours qu'il était ait pu produire quelque chose d'aussi neuf que Gros Câlin. Lorsque l'auteur se dévoilait, on ne voulait pas le croire: «Romain Gary était bien incapable d'avoir écrit cela ${ }^{168}$ ! »

On ne méditera jamais assez ce déni de réalité et on gagnera à en tirer la leçon en l'appliquant au romancier du Satyricon et à celui de l'Histoire Auguste. A-t-on assez répété - reprenant ainsi les vieilles objections d'un Ferdinand Lot ou d'un Michel Rostovtzeff - que Nicomaque Flavien senior, un austère juriste et un zélé fonctionnaire, ne pouvait s'être abaissé à la vulgarité qui caractérise l'Histoire Auguste? «Nicomaque Flavien était bien incapable d'avoir écrit cela! »

“J'étais un auteur classé, catalogué, acquis, ce qui dispensait les professionnels de se pencher vraiment sur mon œuvre et de la connaître » regrettait Gary ${ }^{169}$. D’autres ont catalogué Flavien Préfet du prétoire de Théodose et, à ce titre, lui ont dénié toute fantaisie, toute personnalité, toute conviction. Ils n’ont pas non plus su imaginer que l'homme passait ses veilles nocturnes à combattre secrètement ce

\footnotetext{
165 Vie et mort d'Émile Ajar, Paris, I98ı, p. 43.

166 Ibid., p. 36.

167 Ibid. p. I6-I7.

168 Ibid., p. I7.

${ }^{169}$ Ibid., p.I7.
} 
qu'il faisait mine de servir le jour. Il y a des Pénélope aussi chez les historiographes antiques.

Enfin, le paradigme Ajar, décidément fort opérationnel, offre un dernier point de rencontre avec les méthodes et débats de la philologie classique. Lorsqu'un chercheur rencontre dans deux textes antiques des formulations proches, voire identiques, il a le choix entre deux explications. Les passages en question peuvent avoir été recopiés l'un sur l'autre, dans un ordre qu'il revient au philologue d'établir. Mais ils peuvent constituer également des remplois, auquel cas ils signalent que les deux œuvres en question sont de la même "plume». C'est ce dernier cas de figure qui se présente par exemple pour l'orchestration du chœur d'entrée de la Cantate profane Bwv 205 (“Zerreisset, zersprengt, zertrümmert die Gruft») de Jean-Sébastien Bach, reprise à l'identique (sur d'autres paroles) par le compositeur un an plus tard, en I734, dans l'Oratorio de Noël. Personne ne doute du fait que ces mesures identiques authentifient ces deux compositions comme toutes deux de Bach.

Or Romain Gary, lorsqu'il voulait se défendre (mollement) d'être Émile Ajar, avait un système de défense tout prêt pour répondre aux enquêteurs qui lui soumettaient les similitudes indéniables, de composition, de situation, de style, entre lui-même et Ajar. Il répondait alors : «Évidemment. Personne ne s’est aperçu à quel point Ajar est influencé par moi ${ }^{170}$.) Et il invoquait le plagiat, usant de l'arme de la vanité littéraire pour mieux jeter le doute sur les conclusions justes des observateurs les plus fins. Or le cas se présente plus d'une fois dans l'Histoire Auguste. Alors que tel texte de loi rédigé en 390 par Nicomaque Flavien contre les exolètes mâles et connu par les recueils juridiques anciens se retrouve cité en termes quasi-identiques dans la Vie de Carus de l'Histoire Auguste ${ }^{171}$, les esprits sceptiques, qui ne connaissent pas Émile Ajar, y voient une coïncidence au lieu d'en inférer une identité d'auteur.

Écrire sous un pseudonyme est un moyen de semer ses censeurs, d'amuser une galerie complice et de se libérer des précautions de l'autocensure. Bref, de gagner sa liberté. Pour Gary, Ajar fut «une nouvelle naissance. » Le romancier témoigne: “Je recommençais. Tout m’était donné encore une fois ${ }^{172}$. » Nul doute à mes yeux qu'Encolpius dans la maison de Pline le Jeune et Nicomaque Flavien à la cour de Théodose ont respiré, en rédigeant le Satyricon et l'Histoire Auguste, un même parfum de liberté.

\section{Stéphane Ratti}

Professeur à l'université de Franche-Comté stephane-ratti@wanadoo.fr

170 Ibid., p.38.

171 St. Ratti, «Nicomaque Flavien senior auteur de l'Histoire Auguste», Antiquus error (cité note I64), p. 220-22I ; id., Polémiques entre païens et chrétiens, Paris, 2012, p. I56-i62.

172 Vie et mort d'Émile Ajar, p.3o. 


\section{Bibliographie}

Амpноux, Ch.-B., “Quelques remarques sur la formation, le genre littéraire et la composition de l'Évangile de Marc », Filologia neotestamentaria I9-20, I997, p.5-34.

_, “Le canon du Nouveau Testament avant le Iv $^{\mathrm{e}}$ siècle», Filologia neotestamentaria $2 \mathrm{I}, 2008$, p.9-26.

BlüMel, R., “Mata vita Tau bei Petronius 62 », Philologus, I927, p. 47I-472.

Bowersock, G. W., Le mentir-vrai dans l’Antiquité. La littérature païenne et les évangiles, I994, trad. fr. P.-E. Dauzat, Paris, 2007.

Brown, R.-E., Que sait-on du Nouveau Testament?, trad. fr. J. Mignon, Paris, 2000.

Brunet, C., “La vision de l'affranchi chez Pétrone: terminologie et discours », La fin du statut servile? (affranchissement, libération, abolition...), 3o $\mathrm{o}^{\mathrm{e}}$ colloque du Groupe international de recherches sur l'esclavage dans l'Antiquité (GIREA), Besançon, I5-ı6-I7 décembre 2005: hommage à Jacques Annequin, éd. A. Gonzalès, Besançon, Pufc, 2008, p.25I-262.

Carcopino, J., “Sur les traces de l'hermétisme africain», Aspects mystiques de la Rome païenne, Paris, I942.

Conte, G. B., “Petronius, Sat. I4I, 4”, Classical Quarterly 37, I987, p.529-532.

Cueva, E. P., “The date of Chariton's Chaereas and Callirhoe revisited », Classica et Mediaevalia 5i, 2000, p. 197-208.

Cullmann, O., Le Nouveau Testament, Paris, Ig66.

Cumont, F., Lux perpetua, éd. B. Rochette et A. Motte (Bibliotheca Cumontiana; Scripta Maiora II), Torino-Turnhout, 2oog.

Dubuisson, M., “Aventures et aventuriers dans le Satiricon de Pétrone», Cahiers des paralittératures 5, I993, p.9-23.

Ernout, A., Le Satiricon, Paris, cuf, I923.

Gamba, G. G., Petronio Arbitro e i cristiani: ipotesi per una lettura contestuale del "Satyricon», Rome, I998 (Biblioteca di scienze religiose, I4I).

Gaudemet, J., Institutions de l'Antiquité, Paris, I967.

Gonzalès, A., “Peur des affranchis impériaux et compassion envers les affranchis privés dans l'œuvre de Pline le Jeune », Fear of slaves, fear of enslavement in the ancient Mediterranean = Peur de l'esclave, peur de l'esclavage en Méditerranée ancienne (discours, représentations, pratiques), Actes du XXIX ${ }^{\mathrm{e}}$ colloque du Groupe international de recherche sur l'esclavage dans l'Antiquité (GIREA), Rethymnon, 4-7 novembre 2004, éd. A. Serghidou, Besançon, 2007, p.3o7-324.

Habermehl, P., Satyrica 79-I4I: ein philologisch-literarischer Kommentar. I, Sat. 79-IIo, Berlin-New York, 2006.

Holzberg, N., "Petronii Arbitri Satyricon Ioo-II5: Edizione critica e commento», Classical World I05 (2), 2012, p. 278-279. 
Labriolle, P. de, La réaction païenne. Étude sur la polémique antichrétienne du I $^{\text {r }}$ au vie siècle, Paris, i934, rééd. 2005.

MacMullen, R., Le paganisme dans l'Empire romain, trad. fr. A. Spiquel et A. Rouselle, Paris, I987.

— «What Difference did Christianity make? », Historia 35 (3), I986, p. 322-343, repris dans id., Changes in the Roman Empire: Essays in the Ordinary, Princeton, I990, p. I42-I55.

Martin, R., Le Satyricon. Pétrone, Paris, I999.

Martin, R., "Qui a (peut-être) écrit le Satyricon? ", Revue des Études Latines 78, 2000, p. I39-163.

Monat, P., Histoire profane de la Bible. Origines, transmission et rayonnement du Livre saint, Paris, 2013.

Pepe, L., “Petronio conosce l'epistolario di Plinio », Giornale Italiano di Filologia II, I958, p. 289-294.

Perrochat, P., Pétrone. Le festin de Trimalchion. Commentaire exégétique et critique, Paris, I939.

Ramelli, I. L. E., “Petronio e i cristiani: allusioni al Vangelo di Marco nel Satyricon? „Aevum 70 (I), I996, p. 75-80.

-, “The ancient novels and the New Testament: possible contacts", Ancient Narrative 5, 2007, p.4I-68.

-, “Les vertus de la chasteté et de la piété dans les romans grecs et les vertus des chrétiens : le cas d'Achille Tatius et d'Héliodore ", Passions, vertus et vices dans l'ancien roman, Actes du colloque de Tours, I9-2ı octobre 2006, éd. B.Pouderon et C. Bost-Pouderon, Paris, 20og, p. I49-ı68.

Ratti, St., Écrire l'Histoire à Rome, Paris, 2009 (avec J.-Y. Guillaumin, P.-M. Martin et É. WolfF).

-, Antiquus error. Les ultimes feux de la résistance païenne (Bibliothèque de l'Antiquité Tardive, I4), préf. J.-M. CARrié, Turnhout, 2010.

-, Polémiques entre païens et chrétiens, Paris, 2012.

Ripoll, F., “Le Bellum ciuile de Pétrone: une épopée flavienne? » Revue des Études Anciennes I04 (I-2), 2002, p. I63-I84.

Rossi, G. B. De, La Roma sotterranea cristiana, Roma, t. I, I864; t. II, I867; t. III, I877.

Sснміdт, Th. E., “The letter tau as the Cross: ornament and content in Hebrews 2, I4", Biblica 76 (I), I995, p. 75 -84.

Simon, M., Le Christianisme antique et son contexte religieux, Scripta varia, vol. 2, chapitre «Syncrétisme religieux dans l’Afrique romaine », Tübingen, I98I.

Vannini, G., Petronii Arbitri Satyricon Ioo-II5: edizione critica e commento, BerlinNew York, 2010, Classical World Io5 (2), 2012, p. 278-279.

Veyne, P., “Vie de Trimalcion », La société romaine, Paris, I99I, p. I3-87.

Wolff, É., Pline le Jeune ou le refus du pessimisme, Rennes, 2003. 